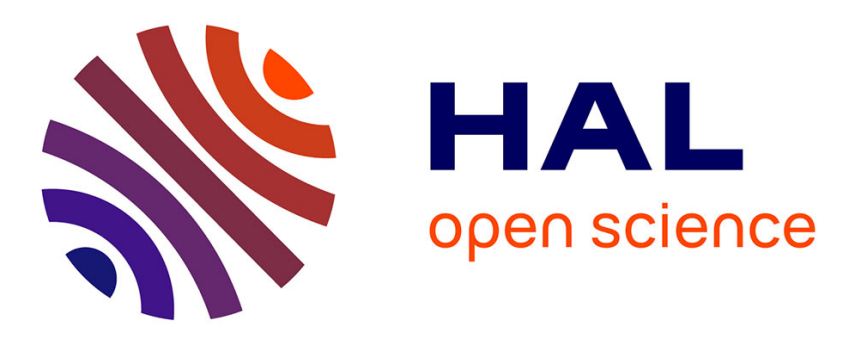

\title{
Cyclodextrin Complexation Studies as the First Step for Repurposing of Chlorpromazine
}

\author{
Zhiqiang Wang, David Landy, Christina Sizun, Christine Cézard, Audrey \\ Solgadi, Cédric Przybylski, Luc De Chaisemartin, Lars Herfindal, Gillian \\ Barratt, François-Xavier Legrand
}

\section{To cite this version:}

Zhiqiang Wang, David Landy, Christina Sizun, Christine Cézard, Audrey Solgadi, et al.. Cyclodextrin Complexation Studies as the First Step for Repurposing of Chlorpromazine. International Journal of Pharmaceutics, 2020, 584, pp.119391. 10.1016/j.ijpharm.2020.119391 . hal-02885940

\author{
HAL Id: hal-02885940 \\ https://hal.science/hal-02885940
}

Submitted on 24 Nov 2020

HAL is a multi-disciplinary open access archive for the deposit and dissemination of scientific research documents, whether they are published or not. The documents may come from teaching and research institutions in France or abroad, or from public or private research centers.
L'archive ouverte pluridisciplinaire HAL, est destinée au dépôt et à la diffusion de documents scientifiques de niveau recherche, publiés ou non, émanant des établissements d'enseignement et de recherche français ou étrangers, des laboratoires publics ou privés. 


\title{
Cyclodextrin complexation studies as the first step for repurposing of chlorpromazine
}

\author{
Zhiqiang Wang ${ }^{\mathrm{a}}$, David Landy ${ }^{\mathrm{b}}$, Christina Sizun ${ }^{\mathrm{c}}$, Christine Cézard ${ }^{\mathrm{d}}$, Audrey Solgadi ${ }^{\mathrm{e}}$, \\ Cédric Przybylski ${ }^{\mathrm{f}}$, Luc de Chaisemartin ${ }^{\mathrm{g}, \mathrm{h}}$, Lars Herfindal ${ }^{\mathrm{i}}$, Gillian Barratt ${ }^{\mathrm{a}}$, \\ François-Xavier Legrand ${ }^{a, *}$ \\ ${ }^{a}$ Université Paris-Saclay, CNRS, Institut Galien Paris-Saclay, 92290 Châtenay-Malabry, France \\ ${ }^{\mathrm{b}}$ Unité de Chimie Environnementale et Interactions sur le Vivant (UCEIV, EA 4492), SFR Condorcet FR CNRS 3417, Université du Littoral Côte d'Opale, 59140 Dunkerque, \\ France \\ ${ }^{\mathrm{c}}$ Université Paris-Saclay, CNRS, Institut de Chimie des Substances Naturelles, UPR 2301, 91198 Gif-sur-Yvette, France \\ ${ }^{\mathrm{d}}$ Laboratoire de Glycochimie, des Antimicrobiens et des Agroressources, CNRS UMR 7378, Université de Picardie Jules Verne, 80000 Amiens, France \\ ${ }^{\mathrm{e}}$ Université Paris-Saclay, Inserm, CNRS, Ingénierie et Plateformes au Service de l'Innovation Thérapeutique, 92290 Châtenay-Malabry, France \\ ${ }^{\mathrm{f}}$ Institut Parisien de Chimie Moléculaire, CNRS UMR 8232, Sorbonne Université, 75005 Paris, France \\ ${ }^{g}$ Service d'Immunologie, Hôpital Bichat-Claude-Bernard, Assistance Publique-Hôpitaux de Paris, 75018 Paris, France \\ ${ }^{\mathrm{h}}$ Université Paris-Saclay, Inserm, Inflammation, Microbiome and Immunosurveillance, 92290 Châtenay-Malabry, France \\ ${ }^{i}$ Department of Clinical Science, University of Bergen, Jonas Lies Vei 87, 5009 Bergen, Norway
}

A R T I C L E I N F O

\section{Keywords:}

Cyclodextrin

Chlorpromazine

Inclusion complex

Sugammadex

Photodegradation

Repurposing

\begin{abstract}
A B S T R A C T
The antipsychotic drug chlorpromazine (CPZ) has potential for the treatment of acute myeloid leukemia, if central nervous system side-effects resulting from its passage through the blood-brain barrier can be prevented. A robust drug delivery system for repurposed CPZ would be drug-in-cyclodextrin-in-liposome that would redirect the drug away from the brain while avoiding premature release in the circulation. As a first step, CPZ complexation with cyclodextrin (CD) has been studied. The stoichiometry, binding constant, enthalpy, and entropy of complex formation between $\mathrm{CPZ}$ and a panel of CDs was investigated by isothermal titration calorimetry (ITC). All the tested CDs were able to include CPZ, in the form of 1:1, 1:2 or a mixture of 1:1 and 1:2 complexes. In particular, a substituted $\gamma$-CD, sugammadex (the octasodium salt of octakis(6-deoxy-6-S-(2-carboxyethyl)-6-thio)cyclomaltooctaose), formed exclusively 1:2 complexes with an extremely high association constant of $6.37 \times 10^{9} \mathrm{M}^{-2}$. Complexes were further characterized by heat capacity changes, one- and twodimensional (ROESY) nuclear magnetic resonance (NMR) spectroscopy and molecular dynamics simulations. Finally, protection of CPZ against photodegradation by CDs was assessed. This was accelerated rather than reduced by complexation with $\mathrm{CD}$. Altogether these results provide a molecular basis for the use of CD in delayed release formulations for $\mathrm{CPZ}$.
\end{abstract}

\section{Introduction}

Cancer chemotherapy continues to be in need of improvements, given the side effects associated with many of the drug used at the moment as well as the problem of resistance. One source of new therapeutic modalities is the repurposing of molecules that are already in use for other pathologies, as reviewed, for example, by Andresen and Gjertsen in the case of acute myeloid leukemia (AML) (Andresen and
Gjertsen, 2017, 2019). Among the molecules that have been considered for repurposing are phenothiazines, a class of drugs active on the central nervous system, have anti-proliferative and pro-apoptotic effects in leukemia cells lines (Zhelev et al., 2004). This phenomenon may be mediated in part by an effect on mitochondrial membranes, since the ATP content of the cells was observed to be reduced. Inhibition of calmodulin and protein kinases, as well as P-glycoprotein involved in multi-drug resistance, has also been reported (Jaszczyszyn et al., 2012).

\footnotetext{
* Corresponding author.

E-mail address: francois-xavier.legrand@universite-paris-saclay.fr (F.-X. Legrand).
} 
<smiles>CN(C)CCCN1c2ccccc2Sc2ccc(Cl)cc21</smiles>

Fig. 1. Structural formula of CPZ.

One molecule from this series, chlorpromazine (CPZ, Fig. 1), was found as early as 1998 to inhibit vincristine transport in multi-drug resistant leukemia cells (Syed et al., 1998), again suggesting a membrane-associated mechanism. CPZ and other phenothiazines are photosensitive and the thiazine dyes methylene blue and toluidine blue can be used for photodynamic therapy of tumors (O'Connor et al., 2009). Based on these results, interest in the use of phenothiazines for the treatment of acute myeloid leukemia (AML) has arisen recently. This form of leukemia is aggressive and usually results in death after two months if untreated. Even when treatment is successful, the relapse rate is high. In particular, leukemic stem cells in the bone marrow appear to survive chemotherapy. In younger patients, the outcome can be improved by allogenic bone marrow transfer, but this option is not available for older patients who, furthermore, poorly tolerate intensive chemotherapy. Therefore, there is a need to find new drugs to add to the current arsenal, which is headed by a combination of cytarabine and daunorubicin (Juliusson et al., 2009; Döhner et al., 2010; Lichtman, 2013).

With this in mind, Rai et al. observed that CPZ inhibited the growth of human AML cell lines in vitro and in mouse xenografts in vivo (Rai et al., 2014). While recent studies have been directed towards developing new phenothiazine derivatives with increased activity against leukemia (Brem et al., 2017), a true repurposing strategy would use a molecule already in clinical use, such as CPZ. However, the use of this drug in a new indication would require a more innovative approach to its formulation than the existing specialities based on CPZ hydrochloride. As a drug active in the central nervous system CPZ crosses the blood-brain barrier freely; however, for the treatment of AML it is necessary to deliver drug to the bone marrow while sparing the brain to avoid side-effects. In terms of modifying the redistribution of an active molecule, liposomes have proved their efficacy in a number of applications, and formulations of anthracyclines destined for cancer chemotherapy are commercially available. Formulations that persist in the circulation and accumulate in tumors can be designed, but in the particular case of $\mathrm{CPZ}$ it is important to control drug release to avoid the possibility of CNS side-effects. Therefore, we have conceived a strategy in which the drug would be first included in a cyclodextrin (CD) and thereafter this complex would be encapsulated in a liposome. This type of double encapsulation approach has already been described in the literature, originally by McCormack and Gregoriadis in 1994 (McCormack and Gregoriadis, 1994) and more recently by several groups as reviewed by Greige-Gerges and coll. (Gharib et al., 2015), and is particularly useful when there is a possibility of interaction of the drug with the liposomal membrane.

A first step in this strategy is to choose appropriate CD that can form high-affinity complexes with the drug in question. CDs are cyclic oligomers of 6,7 or 8 glucose units ( $\alpha$-, $\beta$ - and $\gamma$-CD respectively), providing a central cavity that can accommodate hydrophobic guest molecules. A wide range of pharmaceutical molecules have been formulated as inclusion complexes in order to increase their apparent solubility in aqueous media, improve their bioavailability and stability and reduce their toxicity. Several studies of the complexation of $\mathrm{CPZ}$ with $\mathrm{CD}$ have already been performed; most of them employing $\beta-C D$, sometimes modified with hydrophobic chains, and it was observed that these complexes had 1:1 stoichiometry. Complexation with $\mathrm{CD}$ resulted in a decrease in the haemolytic and photosensitizing side effects of CPZ; without however changing its activity in the central nervous system (Uekama et al., 1981; Irie and Uekama, 1985; Hoshino et al., 1989).

Therefore, in this work, we have undertaken a systematic study of the inclusion of $\mathrm{CPZ}$ in a range of $\mathrm{CDs}$, focussing on native $\mathrm{CD}$ and derivatives that are already included in authorized pharmaceutical products (see Table 1). We have used physico-chemical techniques, and in particular isothermal titration calorimetry (ITC), nuclear magnetic resonance (NMR) spectroscopy and molecular modelling to thoroughly characterize the nature of the complexes formed with each $\mathrm{CD}$. This information will be essential for designing formulations using $\mathrm{CD}$ to control the distribution and biological activity of CPZ.

Table 1

Structural formulae of the CDs used in this study.

\begin{tabular}{|c|c|c|c|c|c|c|}
\hline General structure & Abbreviation & $n$ & $\mathbf{R}_{2}$ & $\mathbf{R}_{3}$ & $\mathbf{R}_{6}$ & DS \\
\hline & $\beta-C D$ & 7 & $\mathrm{OH}$ & $\mathrm{OH}$ & $\mathrm{OH}$ & - \\
\hline & $\gamma-\mathrm{CD}$ & 8 & $\mathrm{OH}$ & $\mathrm{OH}$ & $\mathrm{OH}$ & - \\
\hline & RAME- $\beta$-CD & 7 & & $\mathrm{OCH}_{3}$ or $\mathrm{OH}$ & & 12.6 \\
\hline & DIME- $\beta$-CD & 7 & $\mathrm{OCH}_{3}$ & $\mathrm{OH}$ & $\mathrm{OCH}_{3}$ & 14 \\
\hline & TRIME- $\beta-C D$ & 7 & $\mathrm{OCH}_{3}$ & $\mathrm{OCH}_{3}$ & $\mathrm{OCH}_{3}$ & 21 \\
\hline & SBE- $\gamma-C D$ & 8 & & $\mathrm{OCH}_{2} \mathrm{CH}_{2} \mathrm{CH}_{2} \mathrm{CH}_{2} \mathrm{SO}_{3} \mathrm{Na}$ or $\mathrm{OH}$ & & 7.5 \\
\hline & sugammadex & 8 & $\mathrm{OH}$ & $\mathrm{OH}$ & $\begin{array}{c}\alpha \quad \beta \\
\mathrm{SCH}_{2} \mathrm{CH}_{2} \mathrm{CO}_{2} \mathrm{Na}\end{array}$ & 8 \\
\hline
\end{tabular}




\section{Material and methods}

\subsection{Materials}

Chlorpromazine hydrochloride was purchased from Sigma-Aldrich. $\alpha$-CD (Cavamax ${ }^{\circledR}$ W6 Pharma), RAME- $\beta$-CD (Cavasol ${ }^{\circledR}$ W7 M Pharma), HP- $\beta$-CD (Cavasol ${ }^{\circledR}$ W7 HP Pharma), $\gamma$-CD (Cavamax ${ }^{\circledR}$ W8 Pharma) and HP- $\gamma$-CD (Cavasol ${ }^{\oplus}$ W8 HP Pharma) were gifts from Ashland Global Specialty Chemicals Inc. $\beta$-CD (KLEPTOSE ${ }^{\circledR}$ ) and CRYSME- $\beta$-CD (KLEPTOSE ${ }^{\circledR}$ CRYSMEB EXP) were kindly provided by Roquette Frères. SBE- $\beta$-CD $\left(\right.$ Captisol $^{\oplus}$ ) and SBE- $\gamma$-CD were gifts from Ligand Pharmaceuticals Inc.. Sugammadex (Bridion ${ }^{\circledR}$ ) was kindly provided by Dr. Luc de Chaisemartin of the Bichat Hospital, Paris. DIME- $\beta$-CD and TRIME- $\beta$-CD were purchased, respectively from CycloLab and Biocydex. Potassium phosphate monobasic, ammonium bicarbonate and sodium hydroxide were purchased from Sigma-Aldrich. Promazine sulfoxide was purchased from LGC and 2-hydroxypromazine was obtained from Toronto Research Chemicals Inc. Ultrapure water $\left(\gamma=72.2 \mathrm{mN} \cdot \mathrm{m}^{-1}\right.$ at $22{ }^{\circ} \mathrm{C}$, resistivity $18.2 \mathrm{M} \Omega . \mathrm{cm}$ ) was produced by a Millipore Milli-Q Direct 8 water purification system. Acetonitrile (HPLC grade) and deuterium oxide were acquired from Carlo Erba Reagents and Eurisotop respectively.

\subsection{ITC studies}

Formation constants and inclusion enthalpies were determined simultaneously for each $\mathrm{CD} / \mathrm{CPZ}$ system using an isothermal calorimeter (ITC $_{200}$, MicroCal Inc., USA). CPZ and CD solutions were prepared in phosphate buffer ( $50 \mathrm{mM}, \mathrm{pH}$ 7.0). Firstly, a titration experiment was performed for each system: the sample cell and syringe were filled respectively with a $0.4 \mathrm{mM}$ degassed $\mathrm{CPZ}$ solution $\left(V_{0}=202.8 \mu \mathrm{L}\right)$ and a $5 \mathrm{mM}$ CD solution $(0.25 \mathrm{mM} \mathrm{CPZ}$ and $1.25 \mathrm{mM}$ CD in the case of sugammadex). Secondly, in order to confirm the validity of the chosen stoichiometric model and to increase the accuracy of the thermodynamic parameters, each system (except sugammadex/CPZ) was also submitted to a competition experiment with $\beta$-CD $(0.4 \mathrm{mM} \mathrm{CPZ} \mathrm{solu-}$ tion titrated against a mixture of $2.5 \mathrm{mM} \beta-\mathrm{CD} / 2.5 \mathrm{mM}$ CD solution). For all experiments, after addition of an initial aliquot of $0.2 \mu \mathrm{L}, 10$ aliquots of $3.5 \mu \mathrm{L}$ of the syringe solution were delivered over $7 \mathrm{~s}$ for each injection. This number of ten injections was chosen according to Tellinghuisen's recommendation (Tellinghuisen, 2005). The time interval between two consecutive injections was $70-90 \mathrm{~s}$, which proved to be sufficient for a systematic and complete return to baseline. The agitation speed was set to $1000 \mathrm{rpm}$. The resulting heat flow was recorded as a function of time. Measurements were performed at $25^{\circ} \mathrm{C}$ for all CDs, and also at $13{ }^{\circ} \mathrm{C}$ and $37{ }^{\circ} \mathrm{C}$ for $\beta$-CD, SBE- $\beta$-CD, DIME- $\beta$-CD, $\gamma$-CD, SBE- $\gamma$-CD and sugammadex. Prior to data analysis, blank titrations were carried out under the same experimental conditions by injecting individual species into buffer, and/or buffer into species and buffer into buffer in order to determine the heat of dilution. These values were subtracted from the measured heats in the presence of $\mathrm{CPZ}$ and $\mathrm{CD}$. The peak area following each injection was obtained by integration of the resulting signal and was expressed as the heat effect per injection. The binding constant $\left(K_{B}\right)$, inclusion enthalpy $\left(\Delta_{b} H^{\circ}\right)$ and heat capacity $\left(\Delta_{b} C_{p}{ }^{\circ}\right)$ were determined by the means of an in-house program developed by Bertaut and Landy (2014), involving an overall analysis of all the binding isotherms obtained for a given system: one set of thermodynamic parameters was employed for simultaneous nonlinear regression analyses of titration and competition experiments, carried out at one or three temperatures.

\subsection{NMR studies}

All samples containing CPZ were measured in amber NMR tubes.

One-dimensional ${ }^{1} \mathrm{H}$ and two-dimensional off-resonance ROESY spectra were recorded for $\beta-C D, \gamma-C D$ and DIME- $\beta-C D$ on a Bruker
Avance III spectrometer at a magnetic field of $16.4 \mathrm{~T}$ $\left(\nu\left({ }^{1} \mathrm{H}\right)=699.42 \mathrm{MHz}\right)$ with a PATXI probe equipped with $\mathrm{Z}$ gradients, at a temperature of $25{ }^{\circ} \mathrm{C}$. An improved version of $2 \mathrm{D}$ off-resonance ROESY (Desvaux et al., 1995) was used with a continuous wave (cw) spin-lock of $9.6 \mathrm{kHz}$ and $300 \mathrm{~ms}$ mixing time.

$1 \mathrm{D}{ }^{1} \mathrm{H}$ and off-resonance ROESY spectra of the sugammadex/CPZ system were obtained on a Bruker Avance III spectrometer at a magnetic field of $22.3 \mathrm{~T}\left(\nu\left({ }^{1} \mathrm{H}\right)=950.13 \mathrm{MHz}\right)$ with a cryogenic TCI probe equipped with $\mathrm{Z}$ gradients, at a temperature of $45{ }^{\circ} \mathrm{C} .40 \mathrm{~ms}$ Gaussian pulses were used for selective excitation in 1D ROESY experiments. 1D and 2D ROESY spectra were performed with a $4.5 \mathrm{kHz} \mathrm{cw}$ spin-lock and $200 \mathrm{~ms}$ mixing time.

1D ${ }^{1} \mathrm{H}$ spectra with 3-9-19 water suppression and 2D COSY experiments were acquired at different sugammadex:CPZ ratios on a Bruker Avance III spectrometer at a magnetic field of $14.1 \mathrm{~T}$ $\left(\nu\left({ }^{1} \mathrm{H}\right)=600.13 \mathrm{MHz}\right)$ equipped with a cryogenic Z-gradient TCI probe and a SampleJet sample changer at two temperatures: $25{ }^{\circ} \mathrm{C}$ and $45^{\circ} \mathrm{C}$. Data were analysed by tracing Jobplots. Diffusion ordered spectroscopy, DOSY (Johnson, 1999), was performed under the same conditions with a stimulated echo pulse sequence using $2.0-3.0 \mathrm{~ms}$ bipolar sine gradients, with a power level linearly ramped from 2 to $98 \%$ in 16 steps, and a diffusion time of $100 \mathrm{~ms}$. The water signal was suppressed by excitation sculpting. DOSY data were analysed with an exponential model in Dynamics Center software (Bruker) to extract diffusion coefficients, $D\left(\mathrm{~m}^{2} \cdot \mathrm{s}^{-1}\right)$.

\subsection{Computational studies}

Initial geometries of native $\beta$ - and $\gamma$-CDs and DIME- $\beta$-CD studied in this work were built using the LEaP program from the AmberTools16 distribution (Case et al., 2016). The sugammadex structure was obtained from the Cambridge Structural Database under reference number AWEZIN (Xu et al., 2016). The fragments needed to build the native CDs and DIME- $\beta-C D$ were taken from the R.E.DD.B. database (Dupradeau et al., 2008) under project F-85 (http://q4mdforcefieldtools.org/REDDB/) and the fragments needed to construct the sugammadex and the CPZ ligand were parameterized and defined according to the strategy developed previously (Cézard et al., 2011).

Molecular Dynamics Simulations: The SANDER module of the AmberTools16 program suite was used to perform MD simulations on all the CD/CPZ complexes (Case et al., 2016). The systems were solvated in a truncated octahedral box with a buffer distance of $10.0 \AA$ along with sodium or chlorine counter-ions to neutralize the system's net charge. The q4md-CD force field parameters were used to model the CD systems (Cézard et al., 2011) and the GAFF force field (Wang et al., 2004) was used for the chlorpromazine ligand. The parameters used for water were taken from the TIP3P model (Jorgensen et al., 1983). After minimization, the systems were brought to target temperature by ramping up the temperature over periods of $25 \mathrm{ps}$ followed by a run of 200 ps to relax and equilibrate the system. Classical MD simulations of 50 ns were then performed using the NPT ensemble at a pressure of $1 \mathrm{~atm}$ and a temperature of $300 \mathrm{~K}$. The weak coupling algorithm (Berendsen et al., 1984) was used to regulate the temperature and pressure. The temperature was maintained close to the intended value by weak coupling to an external temperature bath with a relaxation time of $2 \mathrm{ps}$ and the pressure to an external pressure bath of $1 \mathrm{~atm}$ with a coupling constant of 2 ps. The SHAKE algorithm (Ryckaert et al., 1977) was used to constrain C-H bonds, and a time step of $2 \mathrm{fs}$ was used to integrate the equations of motion. Periodic boundary conditions were imposed during simulation. The distance cutoff of $9.0 \AA$ was applied to non-bonded interactions and the PME method (Essmann et al., 1995) was used to compute long-range interactions. Configurations of the systems were stored at intervals of 1 ps. Analyses of the trajectories were performed using the Cpptraj module (Roe and Cheatham, 2013) available in the AmberTools distribution.

$A b$ initio calculations: The conformational space explored using 
molecular dynamics simulations was clustered with Cpptraj (Roe and Cheatham, 2013) and powered by the hierarchical agglomerative approach. A representative structure of each system was obtained by clustering the conformations sampled in the corresponding trajectories into ten representative classes, whose central conformations were further minimized $a b$ initio; the most stable structure among these was retained. All $a b$ initio quantum chemical calculations were performed with the Gaussian09 program (Frisch et al., 2009) at the M06 level of theory (Zhao and Truhlar, 2008) using the $6-31 G^{*}$ basis set. To estimate the influence of solvation, SCRF continuum calculations were made in water $(\varepsilon=78.3553)$.

\subsection{Photodegradation studies}

A CPZ solution was prepared immediately before use at a concentration of $1.4 \mathrm{mM}$ with phosphate buffer (50 mM, pH 7.0). Subsequently, $3 \mathrm{~mL}$ of $13.5 \mathrm{mM} \beta-\mathrm{CD}, 1.93 \mathrm{mM}$ SBE- $\beta-\mathrm{CD}, 2.17 \mathrm{mM}$ DIME- $\beta$-CD, $2.92 \mathrm{mM} \gamma$-CD, $6.3 \mathrm{mM} \mathrm{SBE-} \gamma-\mathrm{CD}$ and $0.7 \mathrm{mM}$ sugammadex solutions were prepared by dissolving the $\mathrm{CD}$ powder in the CPZ solution above and added to quartz cuvettes (Hellma). Photodegradation was investigated by placing the cuvettes at a distance of $2.5 \mathrm{~cm}$ from a UV lamp (VL-6.C from Vilber, wavelength: $254 \mathrm{~nm}$, power: $6 \mathrm{~W}$ ) in a dark room. $100 \mu \mathrm{L}$ from each cuvette was collected at $0,10,20,30,60,120,180,240 \mathrm{~min}$ and mixed with $400 \mu \mathrm{L}$ HPLC mobile phase (acetonitrile/water/0.1 mM ammonium bicarbonate $\mathrm{pH}$ 7.0, 7:2:1, v:v:v). HPLC analysis of the concentration of intact CPZ was performed using a Waters 717 Plus Autosampler HPLC system equipped with Waters 2487 Dual $\lambda$ Absorbance Detector at wavelength of $254 \mathrm{~nm}$ and $309 \mathrm{~nm}$. A C18 chromatographic column (Waters XTerra ${ }^{\circledR}, 5 \mu \mathrm{m}$, $3.0 \times 150 \mathrm{~mm}$ ) was used for separation and was thermostated at $303 \mathrm{~K}$. The mobile phase was comprised of a mixture of acetonitrile, water and $0.1 \mathrm{mM}$ ammonium bicarbonate $\mathrm{pH} 7$ (7:2:1, v:v:v) and the flow rate was set at $0.7 \mathrm{~mL} \cdot \mathrm{min}^{-1}$. The injection volume was $10 \mu \mathrm{L}$. A calibration curve was prepared using $\mathrm{CPZ}$ in mobile phase at concentrations between $5 \mu \mathrm{g} \cdot \mathrm{mL}^{-1}$ and $100 \mu \mathrm{g} \cdot \mathrm{mL}^{-1}$. For a first-order reaction, the reaction kinetic follows the integrated rate low $\ln \left([\mathrm{CPZ}]_{t} /[\mathrm{CPZ}]_{0}\right)=$ $-k \times \mathrm{t}$. So, by plotting $\ln \left([\mathrm{CPZ}]_{t} /[\mathrm{CPZ}]_{0}\right)$ according to time $t$, with $[\mathrm{CPZ}]_{t}$ the chlorpromazine concentration at time $t$ and $[\mathrm{CPZ}]_{0}$ the chlorpromazine concentration at time 0 , we can determine the initial apparent constant $(k=-$ slope) and the half-life time of the reaction $\left(t_{1 / 2}=\ln 2 / k=-\ln 2 /\right.$ slope). LC-HR-MS ${ }^{n}$ analyses were performed using a Dionex Ultimate 3000 system coupled to an electrospray (ESI)LTQ-Orbitrap Velos Pro system (Thermo Fisher Scientific), composed of a double linear trap and an orbital trap. Analyses were carried out in positive ion mode with the same experimental conditions as described above.

\section{Results and discussion}

\subsection{Cyclodextrin screening}

ITC is a very sensitive technique for determining the stoichiometry, binding constant, enthalpy, and entropy of complex formation in a single experiment. Firstly, we observed that complexation of $\mathrm{CPZ}$ with the smallest cyclodextrin, $\alpha$-CD, displays a very weak constant at $25{ }^{\circ} \mathrm{C}$ (see Table 2, entry 1). Indeed, from the fit of the binding isotherm, a stoichiometry, an association constant $K_{B}$ and a binding enthalpy change $\Delta_{b} H^{\circ}$ of $1: 1,1.84 \times 10^{2} \mathrm{M}^{-1}$ and $-12.9 \mathrm{~kJ} \mathrm{~mol}^{-1}$ were found respectively, leading to an entropic term $-\mathrm{T} \times \Delta_{b} S^{\circ}$ equal to $0.0 \mathrm{~kJ} . \mathrm{mol}^{-1}$, indicating that the binding is solely enthalpy-driven. The association constant determined in this study is identical to the value found by Uekama et al. at $25{ }^{\circ} \mathrm{C}$ and at $\mathrm{pH} 7.0$ by UV-visible spectroscopy (Uekama et al., 1978). When a CD of larger cavity size, $\beta-C D$, was selected, a higher association constant and a greater binding enthalpy with CPZ were obtained (see Table 2, entry 2). The association constant of $1.18 \times 10^{4} \mathrm{M}^{-1}$ is very close to the value found by Otagiri et al. at $25{ }^{\circ} \mathrm{C}$ and at $\mathrm{pH} 7.0$ by UV-visible spectroscopy of $1.20 \times 10^{4} \mathrm{M}^{-1}$ (Otagiri et al., 1975), to the value found by Kitamura and Imayoshi at $25{ }^{\circ} \mathrm{C}$ and at pH 7.0 by UV-visible spectroscopy of $1.05 \times 10^{4} \mathrm{M}^{-1}$ (Kitamura and Imayoshi, 1992) and to the value determined by Hardee et al. by isothermal titration calorimetry of $8.32 \times 10^{3} \mathrm{M}^{-1}$ (Hardee et al., 1978). Moreover, a binding enthalpy change $\Delta_{b} H^{\circ}$ and an entropic term $-\mathrm{T} \times \Delta_{b} S^{\circ}$ equal to $-29.9 \mathrm{~kJ} . \mathrm{mol}^{-1}$ and $6.7 \mathrm{~kJ} . \mathrm{mol}^{-1}$ respectively were found, showing that the inclusion of $\mathrm{CPZ}$ in the $\mathrm{CD}$ cavity was completely enthalpy-driven. Hardee et al. were the first to report thermodynamic parameters for the $1: 1 \beta-\mathrm{CD} / \mathrm{CPZ}$ complex with $\Delta_{b} H^{\circ}=-26.8 \mathrm{~kJ} \cdot \mathrm{mol}^{-1}$ and $-\mathrm{T} \times \Delta_{b} S^{\circ}=4.5 \mathrm{~kJ} \cdot \mathrm{mol}^{-1}$ and the values obtained in our study are very close to their values (Hardee et al., 1978). Shiotani et al. found similar values for the thermodynamic parameters at $25{ }^{\circ} \mathrm{C}$, i.e. $\Delta_{b} H^{\circ}=-28.4 \mathrm{~kJ}^{\circ} \mathrm{mol}^{-1}$ and $-\mathrm{T} \times \Delta_{b} S^{\circ}=$ $5.8 \mathrm{~kJ} . \mathrm{mol}^{-1}$ (Shiotani et al., 1994). The negative entropy change could be mainly attributed to the tight binding of guest molecules in the CD cavity, resulting in the loss of freedom of both $\mathrm{CD}$ and guest molecules.

The use of methylated $\beta$-CD derivatives led to very different results, depending on the derivative used. The low and randomly 2-O-methylated- $\beta-C D$, i.e. CRYSME- $\beta-C D$, gave similar results to the $\beta-C D$ (see Table 2 , entry 3 ). In contrast, RAME- $\beta-C D$, a randomly methylated $\beta-C D$ (12.6 $\mathrm{OH}$ groups on average replaced by $\mathrm{OMe}$ at positions 2,3 and 6),

Table 2

Binding constants $K_{\mathrm{B}}$ for association of chlorpromazine with different CDs and related thermodynamic parameters at $\mathrm{T}=25{ }^{\circ} \mathrm{C}$.

\begin{tabular}{|c|c|c|c|c|c|c|c|}
\hline Entry & Cyclodextrin & Stoichiometry & $\boldsymbol{K}_{\boldsymbol{B}}{ }^{1}$ & $\boldsymbol{\Delta}_{\boldsymbol{b}} \boldsymbol{H}^{\circ}{ }^{2}$ & $-\mathbf{T} \times \boldsymbol{\Delta}_{\boldsymbol{b}} \boldsymbol{S}^{\circ 2}$ & $\boldsymbol{\Delta}_{\boldsymbol{b}} \boldsymbol{G}^{\circ 2}$ & $\Delta_{b} C_{p}^{\circ 3}$ \\
\hline 1 & $\alpha-C D$ & $1: 1$ & $(1.84 \pm 0.35) \times 10^{2}$ & $-12.9 \pm 2.0$ & $0 \pm 2.4$ & $-12.9 \pm 0.5$ & n.d. ${ }^{4}$ \\
\hline 2 & $\beta-C D$ & $1: 1$ & $(1.18 \pm 0.02) \times 10^{4}$ & $-29.9 \pm 0.2$ & $6.7 \pm 0.2$ & $-23.2 \pm 0.1$ & $-272.5 \pm 0.1$ \\
\hline 3 & CRYSME- $\beta-C D$ & $1: 1$ & $(1.29 \pm 0.09) \times 10^{4}$ & $-25.9 \pm 0.3$ & $2.4 \pm 0.5$ & $-23.5 \pm 0.2$ & n.d. \\
\hline 4 & RAME- $\beta-C D$ & $1: 1$ & $(6.05 \pm 0.42) \times 10^{3}$ & $-17.2 \pm 0.7$ & $-4.4 \pm 0.9$ & $-21.6 \pm 0.2$ & n.d. \\
\hline 5 & DIME- $\beta$-CD & $1: 1$ & $(2.61 \pm 0.09) \times 10^{4}$ & $-23.7 \pm 0.1$ & $-1.5 \pm 0.2$ & $-25.2 \pm 0.1$ & $-365.7 \pm 0.1$ \\
\hline 6 & HP- $\beta-C D$ & $1: 1$ & $(5.43 \pm 0.72) \times 10^{3}$ & $-17.7 \pm 0.3$ & $-3.6 \pm 0.6$ & $-21.3 \pm 0.3$ & n.d. \\
\hline \multirow[t]{2}{*}{7} & SBE- $\beta-C D$ & $1: 1$ & $(1.99 \pm 0.02) \times 10^{4}$ & $-15.8 \pm 0.2$ & $-8.7 \pm 0.2$ & $-24.5 \pm 0.1$ & $-486.9 \pm 0.1$ \\
\hline & & $1: 2$ & $(2.09 \pm 0.20) \times 10^{3}$ & $-2.9 \pm 0.5$ & $-16.1 \pm 0.8$ & $-18.9 \pm 0.2$ & $309.2 \pm 0.1$ \\
\hline \multirow[t]{2}{*}{8} & $\gamma-\mathrm{CD}$ & $1: 1$ & $(5.34 \pm 1.01) \times 10^{2}$ & $-6.8 \pm 2.2$ & $-8.7 \pm 2.7$ & $-15.6 \pm 0.5$ & $-513.3 \pm 0.1$ \\
\hline & & $1: 2$ & $(5.71 \pm 1.10) \times 10^{3}$ & $-63.5 \pm 4.3$ & $42.0 \pm 4.8$ & $-21.4 \pm 0.5$ & $-385.1 \pm 0.1$ \\
\hline \multirow[t]{2}{*}{9} & $\mathrm{HP}-\gamma-\mathrm{CD}$ & $1: 1$ & $(4.57 \pm 0.84) \times 10^{2}$ & $-8.3 \pm 0.9$ & $-6.9 \pm 1.4$ & $-15.2 \pm 0.5$ & n.d. \\
\hline & & $1: 2$ & $(1.07 \pm 0.41) \times 10^{3}$ & $-42.7 \pm 7.2$ & $25.4 \pm 8.2$ & $-17.3 \pm 1.0$ & n.d. \\
\hline \multirow[t]{2}{*}{10} & SBE- $\gamma-\mathrm{CD}$ & $1: 1$ & $(1.66 \pm 0.17) \times 10^{3}$ & $-3.0 \pm 1.0$ & $-15.4 \pm 1.2$ & $-18.4 \pm 0.2$ & $-608.3 \pm 3.7$ \\
\hline & & $1: 2$ & $(7.38 \pm 0.72) \times 10^{3}$ & $-46.6 \pm 2.0$ & $24.6 \pm 2.2$ & $-22.1 \pm 0.2$ & $-150.2 \pm 7.9$ \\
\hline 11 & sugammadex & $1: 2$ & $(6.37 \pm 0.25) \times 10^{9}$ & $-73.2 \pm 0.3$ & $17.2 \pm 0.4$ & $-55.9 \pm 0.1$ & $-619.2 \pm 0.1$ \\
\hline
\end{tabular}

1 expressed in $\mathrm{M}^{-1}$, except for entry 11 , which is expressed in $\mathrm{M}^{-2}$.

2 expressed in $\mathrm{kJ}^{2} \mathrm{~mol}^{-1}$.

3 expressed in $\mathrm{J} \cdot \mathrm{mol}^{-1} \cdot \mathrm{K}^{-1}$.

${ }^{4}$ n.d. $=$ not determined. 


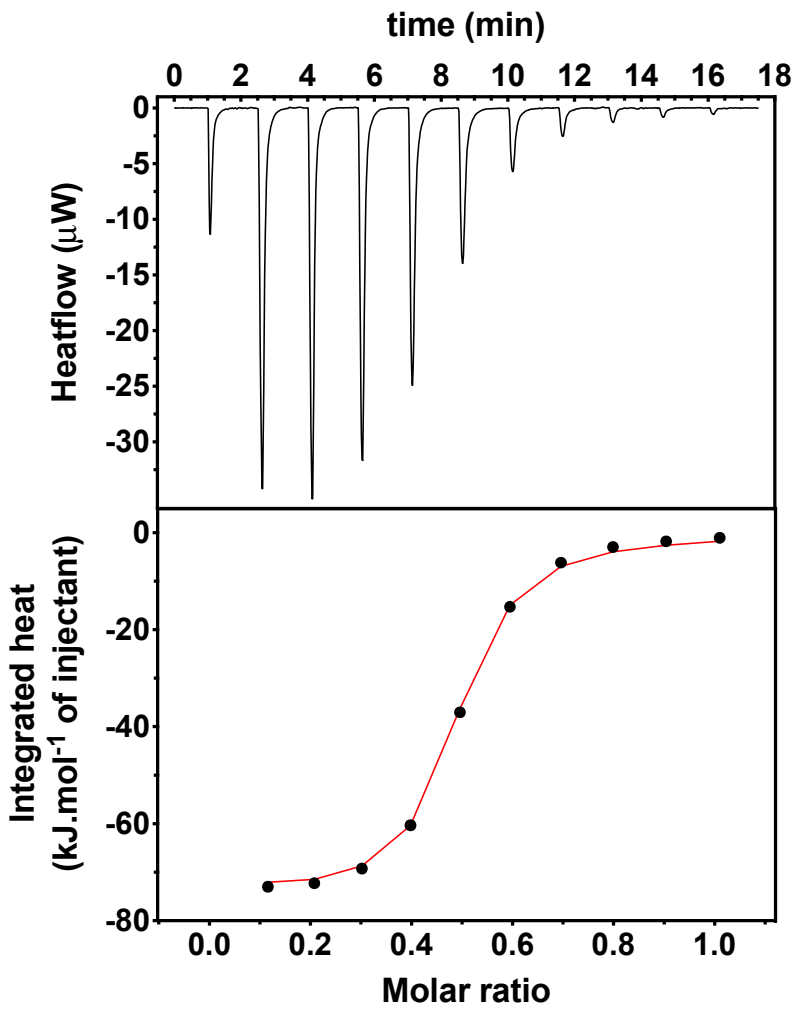

Fig. 2. Thermogram (upper part) and binding isotherm (lower part) for the ITC titration of CPZ $(0.25 \mathrm{mM})$ against sugammadex $(1.25 \mathrm{mM})$, at $25{ }^{\circ} \mathrm{C}$. Dots: experimental isotherm; line: theoretical isotherm obtained by an overall analysis of the experiments performed at 13,25 and $37^{\circ} \mathrm{C}$.

showed a decrease in the association by a factor of two (see Table 2, entry 4). Moreover, in the case of RAME- $\beta$-CD, the entropic contribution is not negligible and contributes to about $20 \%$ of the Gibbs energy change. In order to better understand the impact of methylation, two well-defined methylated $\beta$-CDs were used. On one hand, heptakis(2,6di-O-methyl)- $\beta$-cyclodextrin, or DIME- $\beta$-CD, provided an increase in the association constant by a factor of about two (see Table 2, entry 5). On the other hand, the tri-methylated heptakis(2,3,6-tri-O-methyl)- $\beta$-cyclodextrin was not able to form an inclusion complex with CPZ (data not shown). We can therefore conclude that: (1) methylation of position 2 of the $\beta$-CD does not modify the inclusion properties of the cyclodextrin; (2) methylation of position 6 increases the inclusion capacity, probably by increasing the volume of the cavity and (3) methylation of position 3 has a detrimental effect on the complexation by inducing a steric hindrance on the secondary side. This last point was already observed by Schönbeck et al. during their study on the complexation of bile salts in variously substituted cyclodextrins (Schönbeck et al., 2011, 2014). It should be noted that Uekama's group has reported an association constant for the DIME- $\beta-C D / C P Z$ complex (Ishida et al., 1988). However, the value of the constant $\left(8.80 \times 10^{3} \mathrm{M}^{-1}\right)$ suggests that their study may have been performed with a DIME- $\beta$-CD that contained over-methylated cyclodextrins.

The complexation of CPZ with HP- $\beta-C D$, which is generally recognized as safe and is approved as a pharmaceutical additive, was studied. An association constant and thermodynamic parameters similar to those of RAME- $\beta$-CD were obtained (see Table 2, entry 6 ). Moreover, the value of the association constant is intermediate between the value found by Okimoto et al. from the phase solubility diagram $\left(K_{B}=7.01 \times 10^{3} \mathrm{M}^{-1}\right.$; Okimoto et al., 1999) and that found by Piñero et al. by UV-visible spectroscopy $\left(K_{B}=3.27 \times 10^{3} \mathrm{M}^{-1}\right.$, Piñero et al., 2012) and is close to that reported by Ishida et al. $\left(K_{B}=4.40 \times 10^{3} \mathrm{M}^{-1}\right.$, Ishida et al., 1988).

Next, a second safe and approved modified $\beta$-CD was studied: the well-known sulfobutylated- $\beta$-CD (SBE- $\beta$-CD). The isotherm obtained during the titration of CPZ by SBE- $\beta$-CD was analysed using a two-site binding model involved within a sequential process (see Table 2 , entry 7), in contrast to the unique $1: 1$ stoichiometry observed for the other $\beta$-CDs. The formation of a 1:2 complex can be understood from the enlarged cavity generated by sulfobutyl arms. Nevertheless, the binding constant measured for the 1:1 complex $\left(\kappa_{1: 1}=1.99 \times 10^{4} \mathrm{M}^{-1}\right)$ was one order of magnitude higher than that measured for the 1:2 complex $\left(K_{1: 2}=2.09 \times 10^{3} \mathrm{M}^{-1}\right)$. This difference could arise from a more difficult access of the second $\mathrm{CPZ}$ molecule into the extended $\mathrm{CD}$ cavity. Okimoto et al. studied the SBE- $\beta$-CD/CPZ complex by means of a phase solubility diagram and found a higher association constant of $3.21 \times 10^{4} \mathrm{M}^{-1}$ (Okimoto et al., 1999). This discrepancy can be ascribed to the complexation model used by Okimoto et al., which was a 1:1 model. The thermodynamic parameters reveal that the 1:1 process is enthalpy- and entropy-driven while the entropic component is the main driving force for the following 1:2 step. This favourable entropy change is probably due to the displacement of ordered water molecules around (or inside) the extended cavity.

In the case of $\gamma$-CD and its derivatives, the formation of a 1:2 complex is always observed, implying the use of a sequential model with two binding sites for the adjustment of the binding isotherm. For $\gamma$-CD (see Table 2, entry 8), the 1:2 binding constant was one order of magnitude higher than that measured for the 1:1 complex. In 1978, Uekama et al. found an association constant close to $1.00 \times 10^{3} \mathrm{M}^{-1}$ for a 1:1 complex (Uekama et al., 1978). This stoichiometry is not in agreement with the mixture of stoichiometries found in the present study. On the other hand, using potentiometry, Takisawa et al. found a similar behaviour to that observed in our study with the same magnitude of difference between the two constants (Takisawa et al., 1993). Moreover, these authors explain the great stability of the 1:2 complex by the stacking of the aromatic rings in the large cavity of $\gamma$-CD. From a thermodynamic point of view, the Gibbs energy change of the 1:1 complex is distributed approximately equally between enthalpy and entropy changes, whereas in the case of the 1:2 complex, the complexation is entropically unfavourable $\left(-\mathrm{T} \times \Delta_{b} S^{\circ}=42.0 \mathrm{~kJ} \cdot \mathrm{mol}^{-1}\right)$. But this is counterbalanced by a strong and negative complexation enthalpy change value $\left(\Delta_{b} H^{\circ}=-63.5 \mathrm{~kJ} . \mathrm{mol}^{-1}\right)$, which is the result of van der Waals interactions, $\pi-\pi$ stacking and possibly also hydrogen bonding. The high and positive complexation entropy change is probably derived from the loss of translational and rotational degrees of freedom of $\mathrm{CPZ}$ upon complexation. In the same way as for HP- $\beta-\mathrm{CD}$, the complexation of CPZ with HP- $\gamma-\mathrm{CD}$ is less efficient than with the corresponding native $\mathrm{CD}$ (see Table 2, entry 9) and the 1:2 binding constant value is about twice the 1:1 complexation constant. The thermodynamic parameters show that the $1: 1$ process is enthalpy- and entropy-driven, while, as for the 1:2 step with $\gamma$-CD, the complexation is entropically unfavourable but enthalpically favourable. In the case of SBE- $\gamma-\mathrm{CD}$, as for SBE- $\beta$-CD, the binding constants are higher, indicating that the complexation is more effective with sulfobutyl ether CDs (see Table 2, entry 10). The binding constant measured for the 1:2 complex $\left(\kappa_{1: 2}=7.38 \times 10^{3} \mathrm{M}^{-1}\right)$ was four times higher than that measured for the $1: 1$ complex $\left(K_{1: 1}=1.66 \times 10^{3} \mathrm{M}^{-1}\right)$. Moreover, the thermodynamic parameters for SBE- $\gamma$-CD follow the same trend as for $\gamma$-CD with a preponderant entropic component for the 1:1 process. For the subsequent 1:2 step, as for $\gamma$-CD, complexation is entropically unfavourable, but the high negative enthalpy change value allows to have a negative Gibbs energy change.

Finally, the use of sugammadex led to an unexpected result (Fig. 2). Indeed, the fit of the isotherm obtained during the titration of CPZ by sugammadex reveals a 1:2 stoichiometry (the existence of a complex with a 1:1 stoichiometry could not be excluded but the amount is probably negligible) and an association constant of $6.37 \times 10^{9} \mathrm{M}^{-2}$ (Table 2, entry 11). Hirai et al. were the first to report the formation of pure 1:2 $\gamma$-CD/guest complexes and determined high association constants for these complexes (Hirai et al., 1981). It should be noted that 
the association constant of the $1: 2$ sugammadex/CPZ complex is the second strongest constant reported in the literature for monomeric CDs to our knowledge. Indeed, an association constant equal to $9.0 \times 10^{10} \mathrm{M}^{-2}$ was reported by the group of S.F. Lincoln for the 1:2 $\gamma$-CD/roccelline complex (Clarke et al., 1986). Finally, the thermodynamic parameters of the 1:2 sugammadex/CPZ complex follow the same trend as the other 1:2 complexes; that is, a very negative value for the binding enthalpy change and an unfavourable entropy change.

\subsection{Advanced thermodynamic characterisation}

In order to obtain a deeper insight into the thermodynamic behaviour of the complexes, the binding heat capacity changes were determined for the most promising complexes in terms of stability: i.e. $\beta$ $\mathrm{CD}$ and $\gamma$-CD in their native and sulfobutylated forms, DIME- $\beta$-CD and Sugammadex (see Table 2). The heat capacity change $\Delta_{b} C_{p}{ }^{\circ}$ is defined as the first derivative of binding enthalpy change with temperature at constant pressure. The magnitude and sign of $\Delta_{b} C_{p}{ }^{\circ}$ is directly related to modifications of the well-ordered solvent molecules present around hydrophobic or polar groups of the host and guest molecules. From the temperature dependencies of the binding enthalpy changes, a heat capacity change $\Delta_{b} C_{p}{ }^{\circ}=-272.5 \pm 0.1 \mathrm{~J} \cdot \mathrm{mol}^{-1} \cdot \mathrm{K}^{-1}$ was found for the interaction of $\mathrm{CPZ}$ with $\beta$-CD. The large negative values of the $\Delta_{\mathrm{b}} C_{p}{ }^{\circ}$ reported in this work are to a large extent due to dehydration of the apolar part of the $\mathrm{CD}$ and the guest molecule. In the case of DIME- $\beta$ $\mathrm{CD}$, a larger heat capacity change $\Delta_{b} C_{p}{ }^{\circ}=-365.7 \pm 0.1 \mathrm{~J} \cdot \mathrm{mol}^{-1} \cdot \mathrm{K}^{-1}$ was found, which could be explained by a higher degree of dehydration of the hydrophobic area of the host and the guest. Moreover, the favourable entropic contribution is in agreement with the release of water molecules during the inclusion process. The complexation of $\mathrm{CPZ}$ towards SBE- $\beta$-CD leads to contrasting results: for the 1:1 complex, a negative heat capacity change $\Delta_{b} C_{p}{ }^{\circ}=-486.9 \pm 0.1 \mathrm{~J} \cdot \mathrm{mol}^{-1} \cdot \mathrm{K}^{-1}$ was determined while a positive heat capacity change $\Delta_{b} C_{p}{ }^{\circ}=309.2 \pm 0.1 \mathrm{~J} \cdot \mathrm{mol}^{-1} \cdot \mathrm{K}^{-1}$ was found for the $1: 2$ complex. If the expulsion of water molecules induced by the inclusion of the first $\mathrm{CPZ}$ molecules may be considered as responsible for a negative heat capacity change, the positive value observed for the second encapsulated CPZ molecule probably reflects a conformational change of the $\mathrm{CD}$ during the inclusion process (Brocos et al., 2011). This conformational rearrangement corresponds to the passage from a flexible $\mathrm{CD}$ molecule to a tight one. So, during the inclusion of the second $\mathrm{CPZ}$ molecule, the disordered sulfobutyl arms must be rearranged to encapsulate the second molecule, since the $\beta$-CD macrocycle is unable to bind two CPZ molecules. This rearrangement seems to have a stronger influence on the heat capacity change $\Delta_{b} C_{p}{ }^{\circ}$ than the concomitant displacement of ordered water molecules around the extended cavity.

For the $\gamma-\mathrm{CD} / \mathrm{CPZ}$ system, heat capacity changes $\Delta_{b} C_{p}{ }^{\circ}=-513.3 \pm 0.1$ and $-385.1 \pm 0.1 \mathrm{~J} \cdot \mathrm{mol}^{-1} \cdot \mathrm{K}^{-1}$ were found for the inclusion complexes $1: 1$ and $1: 2$ respectively. The more negative value for the 1:1 complex compared with the $\beta-\mathrm{CD} / \mathrm{CPZ}$ complex is the reflection of a larger number of water molecules involved during the inclusion process. Moreover, the less negative value for the 1:2 complex compared with the 1:1 complex could indicate a smaller number of water molecules involved during the complexation, but a concomitant conformational rearrangement of the $\gamma$-CD macrocycle cannot be excluded. Similar behaviour was observed for the SBE- $\gamma-\mathrm{CD} / \mathrm{CPZ}$ system $\left(\Delta_{b} C_{p}^{\circ}=-608.3 \pm 3.7\right.$ and $-150.2 \pm 7.9 \mathrm{~J} \cdot \mathrm{mol}^{-1} \cdot \mathrm{K}^{-1}$ for the inclusion complexes 1:1 and 1:2 respectively). The lower heat capacity change value obtained for the $1: 1$ complex in the case of the SBE- $\gamma$-CD compared with the $\gamma$-CD could be explained in the same way as the $1: 1$ SBE- $\beta$-CD/CPZ system. Furthermore, the less negative value obtained for the 1:2 SBE- $\gamma$-CD/CPZ inclusion complex compared with the 1:2 $\gamma$ $\mathrm{CD} / \mathrm{CPZ}$ is probably the result of the rearrangement of sulfobutyl arms as for the 1:2 SBE- $\beta$-CD/CPZ. Finally, the heat capacity change obtained for the $1: 2$ sugammadex/CPZ complex $\left(\Delta_{b} C_{p}{ }^{\circ}=-619.2 \pm 0.1 \mathrm{~J} \cdot \mathrm{mol}^{-1} \cdot \mathrm{K}^{-1}\right)$ is of the same order of

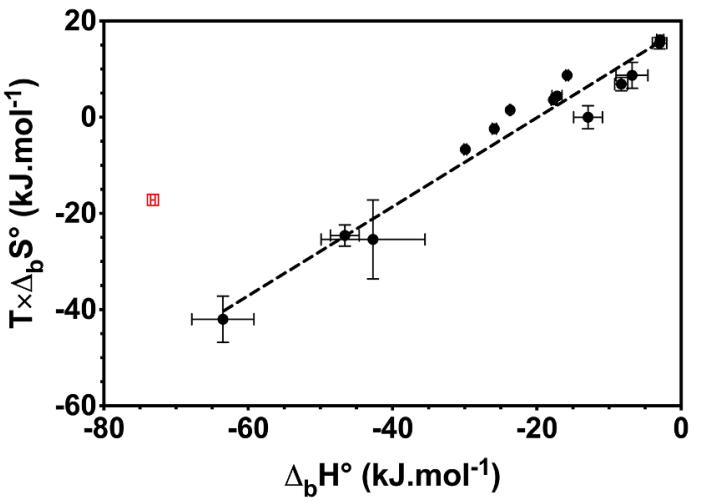

Fig. 3. Enthalpy-entropy compensation plot for the inclusion complexation of $\mathrm{CPZ}$ with various CDs obtained in the present work in an aqueous buffer solution at $25{ }^{\circ} \mathrm{C}$ (the red hollow square corresponds to the sugammadex/CPZ complex).

magnitude as the $1: 1 \mathrm{SBE}-\gamma-\mathrm{CD} / \mathrm{CPZ}$ system and can be explained by the fact that sugammadex can encapsulate two CPZ molecules with or without a small amount of conformational rearrangement.

Enthalpy-entropy compensation has often been observed empirically for inclusion processes in the supramolecular chemistry field (Rekharsky and Inoue, 1998). This relationship between the enthalpy and entropy of binding suggest that the enthalpic changes are offset by the entropic changes (Fig. 3). The observed linear relationship in enthalpy-entropy compensation plots follows from $\mathrm{T} \times \Delta_{b} \mathrm{~S}^{\circ}=\alpha \times \Delta_{b} \mathrm{H}^{\circ}$ $+\mathrm{T} \times \Delta_{b} \mathrm{~S}_{0}^{\circ}$ implying that the changes in entropy of binding are dependent on enthalpy of binding with a slope $\alpha$ and an intercept $\mathrm{T} \times \Delta_{b} \mathrm{~S}^{\circ}{ }_{0}$. The slope $\alpha$ and intercept $\mathrm{T} \times \Delta_{b} \mathrm{~S}^{\circ}{ }_{0}$ of the $\mathrm{T} \times \Delta_{b} \mathrm{~S}^{\circ} v s . \Delta_{b} \mathrm{H}^{\circ}$ plot have been proposed as quantitative measurements of the conformational change and the extent of desolvation upon complex formation, respectively. In accordance with this, the $\mathrm{T} \times \Delta_{b} \mathrm{~S}^{\circ}$ are plotted against the $\Delta_{b} \mathrm{H}^{\circ}$ to obtain a good straight line with a correlation coefficient $r=0.978$, if we except the point corresponding to the sugammadex/CPZ complex, whose symbol is a red hollow square, which falls outside the correlation (Fig. 3). The slope $\alpha=0.93 \pm 0.06$, comprised between the values reported by Rekharsky and Inoue for natural and modified CDs, indicates a rearrangement of the peripheral hydrogen bond network and the accompanying skeletal conformational changes, while the intercept $\left(\mathrm{T} \times \Delta_{b} \mathrm{~S}^{\circ}{ }_{0}=18.4 \pm 1.6 \mathrm{~kJ} . \mathrm{mol}^{-1}\right)$, very close to the value reported by Rekharsky and Inoue for modified CDs, means that fairly extensive dehydration occurs upon inclusion. The fact that the sugammadex/CPZ complex does not follow the general trend underlines the specific influence of the sulfur atoms at C6 position, as already pointed out not only by the unique $1: 2$ stoichiometry of this system but also by its massive enthalpic stabilization, leading to an outstanding affinity.

In order to assess the structural basis of the inclusion mechanisms hypothesized by our thermodynamic study, NMR and molecular modelling investigations were then carried out on the well-defined cyclodextrins $\beta$-CD, DIME- $\beta-C D, \gamma-C D$ and sugammadex.

\subsection{Structure of the $\beta$-cyclodextrin/chlorpromazine complex}

As only few publications report the 1D NMR spectrum of the $\beta$-CD/CPZ complex (Otagiri et al., 1975; Takamura et al., 1983), the ${ }^{1} \mathrm{H}$ NMR spectrum of an equimolar mixture of $\beta-\mathrm{CD}$ and $\mathrm{CPZ}$ was recorded in deuterium oxide at $25^{\circ} \mathrm{C}$. A comparison of ${ }^{1} \mathrm{H}$ NMR spectra of $\beta$-CD $\left(1 \mathrm{mM}\right.$ in $\mathrm{D}_{2} \mathrm{O}$ ) in the presence and absence of $\mathrm{CPZ}$ (Fig. 4) was performed to highlight chemical shift variations of the $\mathrm{H}_{3}$ and $\mathrm{H}_{5}$ protons located inside the $\beta$-CD cavity and of the $\mathrm{H}_{6}$ protons located on the periphery of the cavity. The addition of $\mathrm{CPZ}$ to $\beta$-CD led to an upfield chemical shift variation of $\mathrm{H}_{3}, \mathrm{H}_{5}$ and $\mathrm{H}_{6} / \mathrm{H}_{6}$, consistent with the 

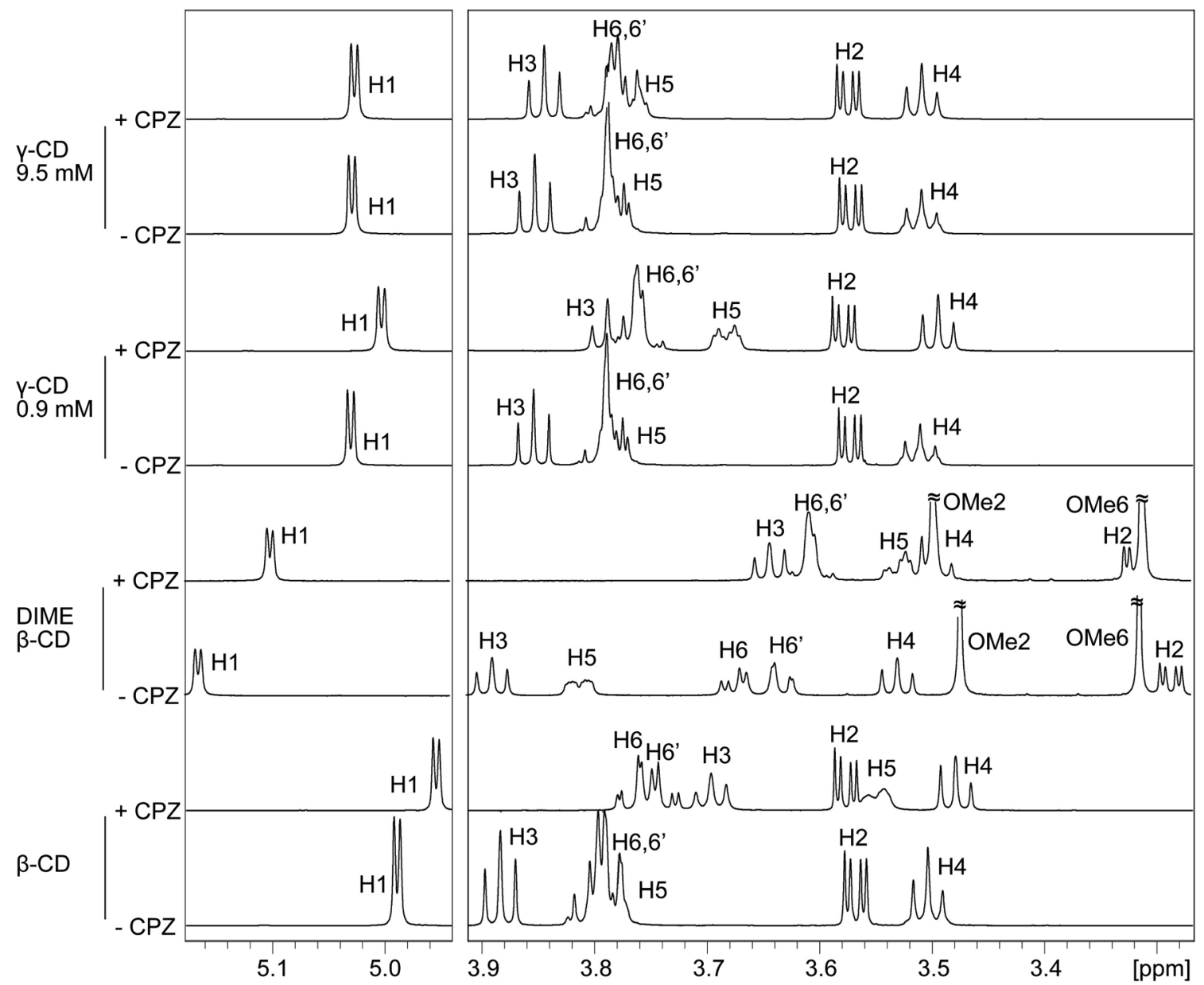

Fig. 4. ${ }^{1} \mathrm{H}$ NMR spectra of $1 \mathrm{mM}$ of $\beta-\mathrm{CD}, 1 \mathrm{mM}$ of DIME- $\beta-\mathrm{CD}, 0.9 \mathrm{mM}$ of $\gamma$-CD or $9.5 \mathrm{mM}$ of $\gamma$-CD in $\mathrm{D}_{2} \mathrm{O}$ with or without $1 \mathrm{mM}$ of $\mathrm{CPZ}\left(\mathrm{T}=25{ }^{\circ} \mathrm{C}, 700 \mathrm{MHz}\right.$ ).

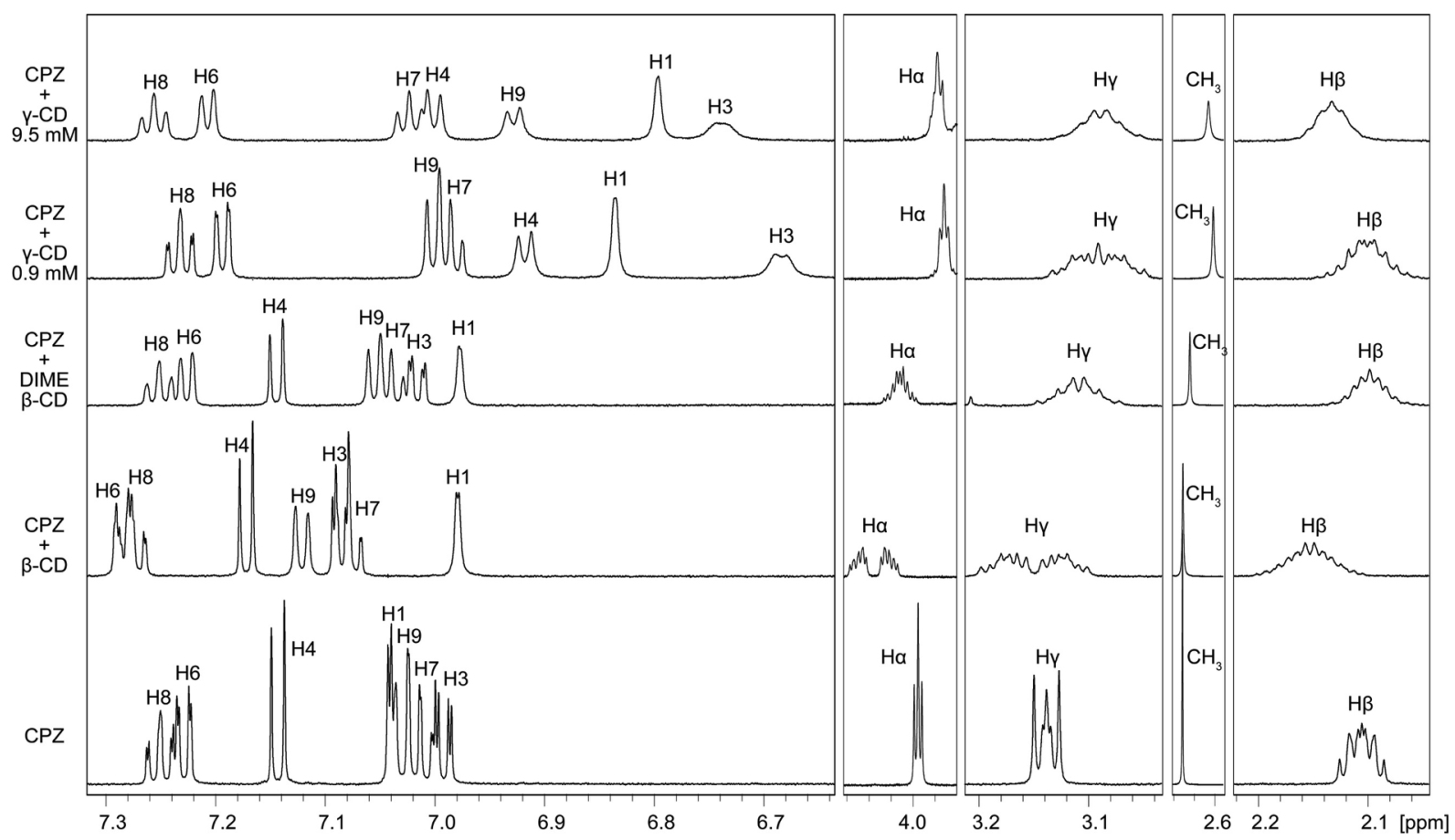

Fig. 5. ${ }^{1} \mathrm{H}$ NMR spectra of $1 \mathrm{mM}$ of $\mathrm{CPZ}$ in $\mathrm{D}_{2} \mathrm{O}$ and in the presence of $1 \mathrm{mM}$ of $\beta-\mathrm{CD}, 1 \mathrm{mM}$ of DIME- $\beta-\mathrm{CD}, 0.9 \mathrm{mM}$ of $\gamma-\mathrm{CD}$ or $9.5 \mathrm{mM}$ of $\gamma-\mathrm{CD}\left(\mathrm{T}=25{ }^{\circ} \mathrm{C}, 700 \mathrm{MHz}\right.$ ). 


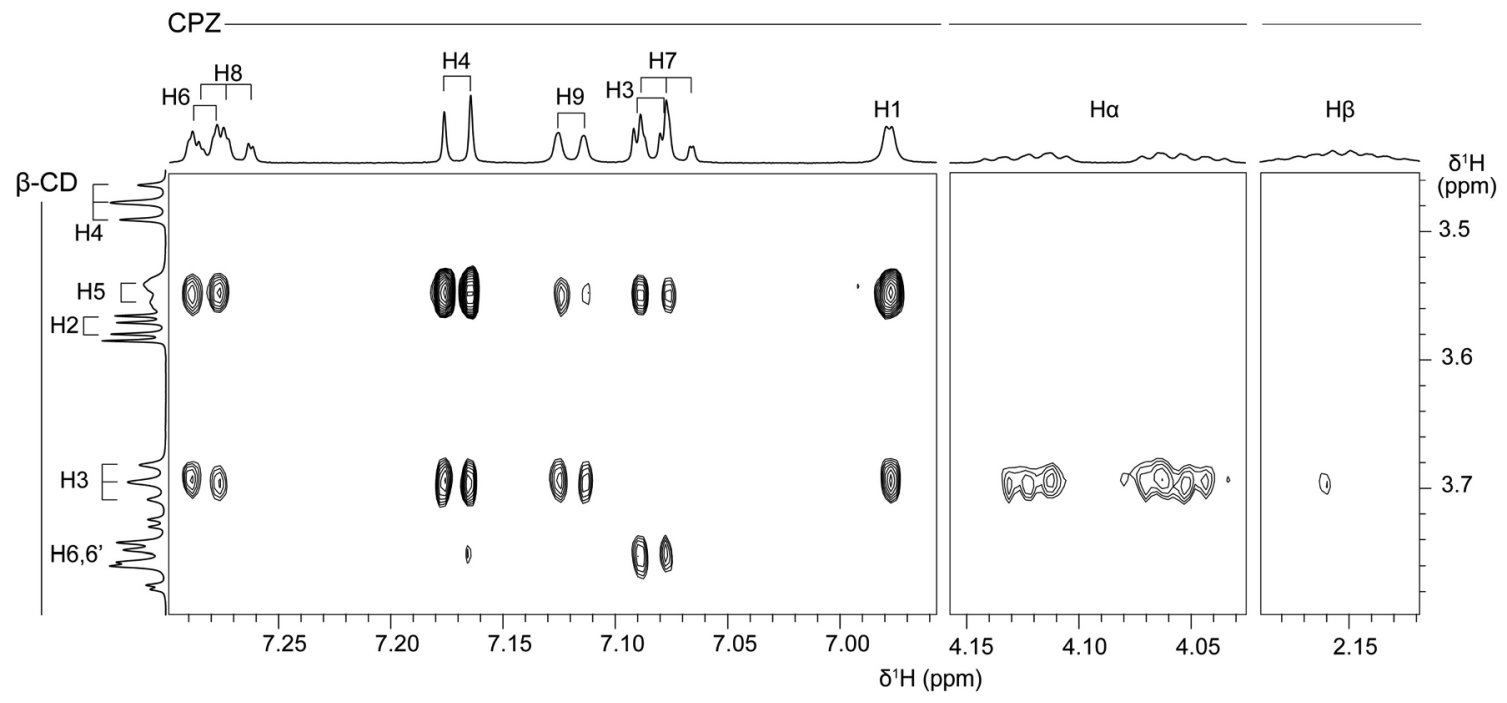

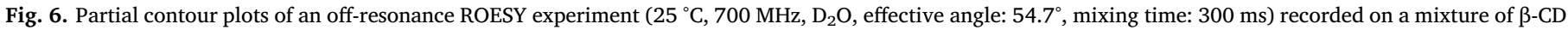
$(1 \mathrm{mM})$ and $\mathrm{CPZ}(1 \mathrm{mM})$.

formation of an inclusion complex. Moreover, the $\mathrm{H}_{1}, \mathrm{H}_{2}$ and $\mathrm{H}_{4}$ protons located outside the $\beta$-CD cavity were also affected during the inclusion process, as an upfield chemical shift variation was observed for the $\mathrm{H}_{1}$ and $\mathrm{H}_{4}$ protons, while the $\mathrm{H}_{2}$ protons displayed a small downfield chemical shift variation. In the case of $\mathrm{CPZ}$, it should be noted that all protons (except the methyl protons) were affected by the complexation into $\beta$-CD (Fig. 5). With the exception of the $\mathrm{H}_{1}$ proton of the $\mathrm{CPZ}$, the formation of an inclusion complex causes downfield shifts in the plane of the aromatic rings. Moreover, upfield shifts of all methylene protons as a result of the addition of the $\beta$-CD were also found. A splitting of the three methylene peaks was observed to result from the formation of an inclusion complex. This effect was most pronounced with the $\mathrm{H}_{\alpha}$ methylene protons, whereas the $\mathrm{H}_{\beta}$ protons were less affected. In order to have a better insight into the three-dimensional structure of the inclusion complex, an off-resonance ROESY experiment was performed on the same $\beta-\mathrm{CD} / \mathrm{CPZ}$ mixture (Fig. 6). This revealed dipolar contacts between $\mathrm{CPZ}$ and $\mathrm{CD}$ cavity protons. Very strong interactions were observed between the $\mathrm{H}_{5}$ protons of $\beta-\mathrm{CD}$ and the $\mathrm{H}_{1}$, $\mathrm{H}_{4}$ and $\mathrm{H}_{6}$ protons of $\mathrm{CPZ}$, as well as strong interactions between the $\mathrm{H}_{3}$ protons of $\beta-C D$ and the $\mathrm{H}_{1}, \mathrm{H}_{4}, \mathrm{H}_{6}$ and $\mathrm{H}_{9}$ protons of the aromatic moiety of CPZ. Weaker interactions involving the $\mathrm{H}_{5}$ protons of $\beta-C D$ and the $\mathrm{H}_{3}$ and $\mathrm{H}_{9}$ protons of $\mathrm{CPZ}$ as well as the $\mathrm{H}_{6} / \mathrm{H}_{6^{\prime}}$ protons of $\beta-\mathrm{CD}$ and the $\mathrm{H}_{3}$ and $\mathrm{H}_{4}$ protons of $\mathrm{CPZ}$ were also detected. No interaction between the aromatic $\mathrm{H}_{7}$ and $\mathrm{H}_{8}$ protons of $\mathrm{CPZ}$ and the $\mathrm{H}_{3}$ and $\mathrm{H}_{5}$ protons located inside the $\beta$-CD cavity were observed, indicating that a part of the aromatic ring was outside the CD cavity. Moreover, for the aliphatic part of CPZ, a strong interaction with the $\mathrm{H}_{\alpha}$ protons and a weaker one with the $\mathrm{H}_{\beta}$ protons were detected with the $\mathrm{H}_{3}$ protons of the $\beta$-CD. All this information suggests that $\mathrm{CPZ}$ enters the $\beta$-CD by the wider side of the rim and the chlorinated aromatic part of CPZ is deeply included within the $\beta$-CD cavity. It should be noted that Piñero et al. showed that the same inclusion mechanism led to the lowest energy during a computational study of the interaction of CPZ with HP- $\beta-C D$ (Piñero et al., 2012).

Finally, molecular dynamics simulations of the complex, taking into account the results of ${ }^{1} \mathrm{H}$ NMR spectroscopy, were undertaken in an attempt to have a better representation of the $\beta-\mathrm{CD} / \mathrm{CPZ}$ complex. The snapshots were clustered into 10 structures to provide a reliable ensemble of representative conformations. The best representative structure, compatible with 2D NMR spectroscopy, was further minimized by DFT calculations (Fig. 7). This structure totally explains the 2D NMR spectroscopy results, especially the lack of cross-correlation between the $\mathrm{H}_{7}$ and $\mathrm{H}_{8}$ protons of $\mathrm{CPZ}$ and the $\mathrm{H}_{3}$ protons of $\beta-C D$, since the mean distances $\mathrm{H}_{7}-\mathrm{H}_{3}$ and $\mathrm{H}_{8}-\mathrm{H}_{3}$ (considering only the 3 closest $\mathrm{H}_{3}$ protons) were equal to 5.2 and $6.0 \AA$ for the $\mathrm{H}_{7}$ and $\mathrm{H}_{8}$ protons respectively. Moreover, the mean distances $\mathrm{H}_{3}-\mathrm{H}_{6} / \mathrm{H}_{6^{\prime}}$ (considering the 2 nearest $\mathrm{H}_{6}$ or $\mathrm{H}_{6^{\prime}}$ protons) and $\mathrm{H}_{4}-\mathrm{H}_{6} / \mathrm{H}_{6^{\prime}}$ (considering the 3 closest $\mathrm{H}_{6}$ or $\mathrm{H}_{6}$, protons) were equal to 3.6 and $4.3 \AA$ for the $\mathrm{H}_{3}$ and $\mathrm{H}_{4}$ protons respectively, corroborating a strongest cross-correlation peak for the proton $\mathrm{H}_{3}$ with the protons $\mathrm{H}_{6}$ or $\mathrm{H}_{6^{\prime}}$ of the $\beta$ - $\mathrm{CD}$. As far as the aliphatic protons of the $\mathrm{CPZ}$ chain were concerned, the mean distances $\mathrm{H}_{\alpha}-\mathrm{H}_{3}$ and $\mathrm{H}_{\beta}-\mathrm{H}_{3}$ (considering the 3 closest $\mathrm{H}_{3}$ protons) were equal to 2.8 and
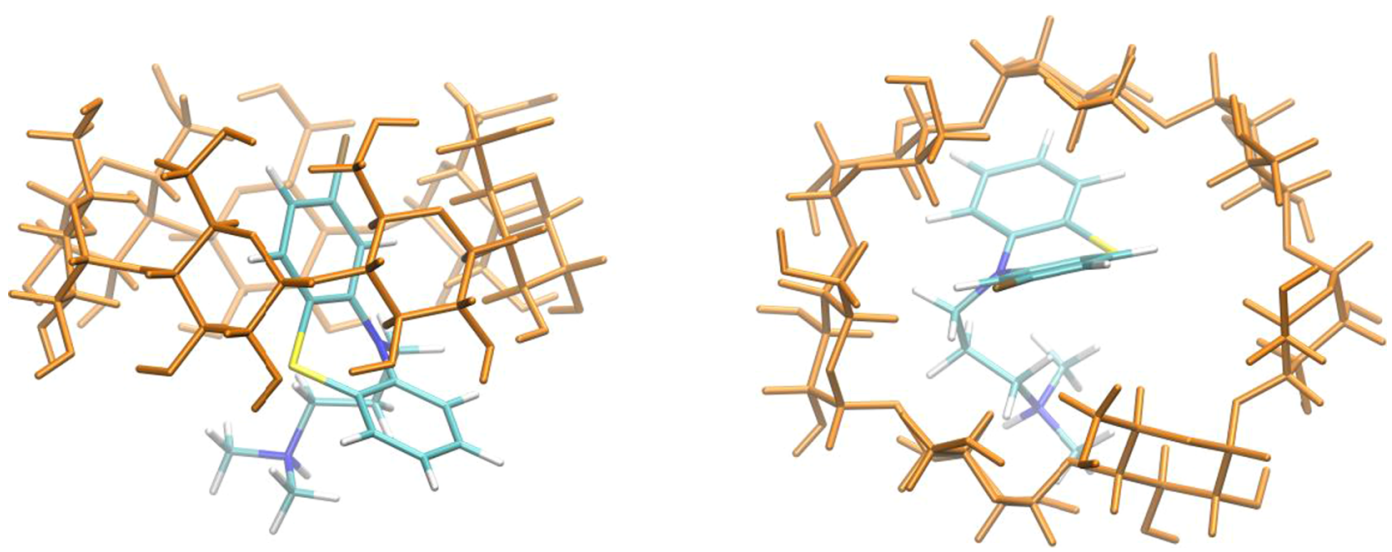

Fig. 7. Proposed molecular structure of $\beta-\mathrm{CD} / \mathrm{CPZ}$ complex with side and top views. 


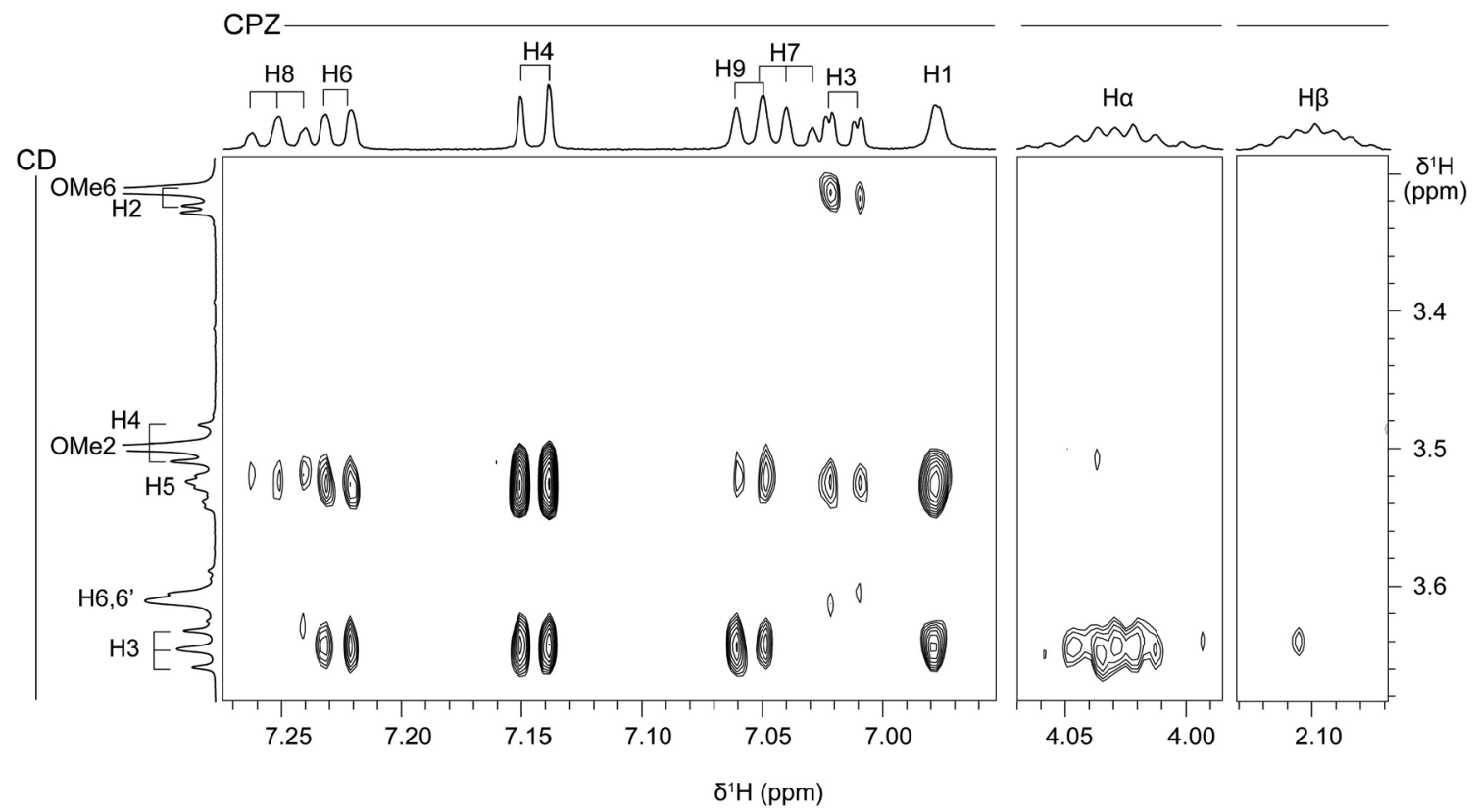

Fig. 8. Partial contour plots from an off-resonance ROESY experiment $\left(25^{\circ} \mathrm{C}, 700 \mathrm{MHz}, \mathrm{D}_{2} \mathrm{O}\right.$, effective angle: $54.7^{\circ}$, mixing time: $\left.300 \mathrm{~ms}\right)$ recorded on a mixture of DIME- $\beta$-CD $(1 \mathrm{mM})$ and CPZ $(1 \mathrm{mM})$.

$4.3 \AA$ and were in accordance with the strong and weak cross-correlation peaks observed for the $\mathrm{H}_{\alpha}$ and $\mathrm{H}_{\beta}$ protons of the CPZ molecule toward the $\mathrm{H}_{3}$ protons of the $\beta-\mathrm{CD}$.

\subsection{Structure of the heptakis(2,6-di-O-methyl)- $\beta$-cyclodextrin/ chlorpromazine complex}

As the heptakis(2,6-di-O-methyl)- $\beta$-cyclodextrin, more often called DIME- $\beta-C D$, is a well-defined cyclodextrin and gives a pure 1:1 complex, a precise structural characterization was carried out using ${ }^{1} \mathrm{H}$ NMR spectroscopy. Similarly to the observations with $\beta$-CD (Fig. 4), addition of CPZ to DIME- $\beta$-CD led to an upfield chemical shift variation of the internal $\mathrm{H}_{3}$ and $\mathrm{H}_{5}$ protons, of the peripheral $\mathrm{H}_{6} / \mathrm{H}_{6}$, protons and of the external $\mathrm{H}_{1}$ and $\mathrm{H}_{4}$ protons and to a downfield chemical shift variation of the external $\mathrm{H}_{2}$ protons. Moreover, the protons of the two methoxy groups located on the periphery of the $\mathrm{CD}$ cavity were also affected during the inclusion process, as a small upfield chemical shift variation was observed for the $\mathrm{O}_{6}-\mathrm{CH}_{3}$ protons while the $\mathrm{O}_{2}-\mathrm{CH}_{3}$ protons led to a downfield chemical shift variation. For the CPZ protons, the ${ }^{1} \mathrm{H}$ NMR spectra show a more complex situation, with slight broadening of the majority of the protons (Fig. 5). Unlike in the $\beta$-CD/ CPZ complex, the chemical shift of the $\mathrm{H}_{8}$ proton of $\mathrm{CPZ}$ remained unchanged but a broadening was observed. As for the $\beta-\mathrm{CD} / \mathrm{CPZ}$ complex, an upfield chemical shift variation was observed for the $\mathrm{H}_{1}$ proton of CPZ. However, a small upfield chemical shift variation was observed for the $\mathrm{H}_{6}$ proton, in contrast to the $\beta-\mathrm{CD} / \mathrm{CPZ}$ complex. Moreover, the formation of an inclusion complex caused downfield shifts of the other protons $\left(\mathrm{H}_{3}, \mathrm{H}_{4}, \mathrm{H}_{7}\right.$ and $\left.\mathrm{H}_{9}\right)$ of the two aromatic rings. Considering the aliphatic chain of $\mathrm{CPZ}$, an upfield chemical shift variation was observed for all protons ( $\mathrm{N}-\mathrm{CH}_{3}$ protons included) except for the $\mathrm{H}_{\alpha}$ protons, for which an increase in the chemical shift was noticed. Furthermore, unlike in the $\beta-\mathrm{CD} / \mathrm{CPZ}$ complex, no clear splitting was observed for the methylene protons.

In order to obtain information about the spatial proximity of $\mathrm{CPZ}$ protons towards CD protons, a 2D off-resonance ROESY spectrum was recorded (Fig. 8). In contrast to the $\beta-\mathrm{CD} / \mathrm{CPZ}$ complex, a weak and a very weak interaction between the aromatic $\mathrm{H}_{8}$ proton of $\mathrm{CPZ}$ and the $\mathrm{H}_{3}$ and $\mathrm{H}_{5}$ protons respectively of DIME- $\beta$-CD were detected, but, as for the $\beta-\mathrm{CD} / \mathrm{CPZ}$ complex, no interaction of the internal $\mathrm{CD}$ proton with the $\mathrm{H}_{7}$ proton of $\mathrm{CPZ}$ was observed, indicating that a smaller part of the aromatic ring was outside the $\mathrm{CD}$ cavity. Comparable strengths of interactions were observed from the cross-correlation peaks between the other aromatic protons of $\mathrm{CPZ}$ and the internal $\mathrm{H}_{3}$ and $\mathrm{H}_{5}$ protons of DIME- $\beta$-CD. Moreover, a very weak interaction involving the $\mathrm{H}_{6} / \mathrm{H}_{6}$, protons of the DIME- $\beta$-CD and the $\mathrm{H}_{3}$ proton of $\mathrm{CPZ}$ was detected, as well as a weak interaction between the same $\mathrm{CPZ}$ proton towards the methoxy protons $\mathrm{O}_{6}-\mathrm{CH}_{3}$, suggesting that the mechanism of inclusion was not perturbed by the methylation of the $\beta-\mathrm{CD}$ macrocycle. Finally, the same interactions as in the $\beta-\mathrm{CD} / \mathrm{CPZ}$ complex were detected between the methylene protons of $\mathrm{CPZ}$ and the internal protons of the $\mathrm{CD}$, and a very weak interaction between with the $\mathrm{H}_{\alpha}$ protons and the methoxy $\mathrm{O}_{2}-\mathrm{CH}_{3}$ protons. With these structural data, a molecular dynamics simulation combined with DFT calculations was carried out and the geometry of the DIME- $\beta-\mathrm{CD} / \mathrm{CPZ}$ complex was obtained. The threedimensional structure of the DIME- $\beta-\mathrm{CD} / \mathrm{CPZ}$ complex is very close to that of the $\beta-\mathrm{CD} / \mathrm{CPZ}$ complex (Fig. 9).

\subsection{Structure of the $\gamma$-cyclodextrin/chlorpromazine complexes}

Only one report in the literature describes the ${ }^{1} \mathrm{H}$ NMR spectrum of the $\gamma$-CD/CPZ complex (Takamura et al., 1983). However, these authors described the $\gamma$-CD/CPZ complex as a 1:2 complex. In our hands, since two $\gamma$-CD/CPZ complexes, with 1:1 and 1:2 stoichiometry, coexist in solution, the $\gamma$-CD concentration was optimised in order to maximise the amount of each complex. The use of a low concentration of $\gamma$-CD gave the maximum yield of the $\gamma-\mathrm{CD} / \mathrm{CPZ}_{2}$ complex (Fig. S1). In particular, the use of a $\gamma$-CD concentration equal to $0.87 \mathrm{mM}$ led to a mixture containing $40 \%$ of free $\mathrm{CPZ}, 11 \%$ of the $\gamma-\mathrm{CD} / \mathrm{CPZ}$ complex and $49 \%$ of the $\gamma-\mathrm{CD} / \mathrm{CPZ}_{2}$ complex in terms of CPZ concentration (Fig. S1). On the other hand, if a $\gamma$-CD concentration of $9.5 \mathrm{mM}$ was used, the mixture contained $9 \%$ of free $\mathrm{CPZ}, 44 \%$ of the $\gamma-\mathrm{CD} / \mathrm{CPZ}$ complex and $47 \%$ of the $\gamma-\mathrm{CD} / \mathrm{CPZ}_{2}$ complex, corresponding to the best compromise between the $\gamma$-CD/CPZ concentration and the amount of free $\gamma$-CD (Fig. S1). Firstly, the ${ }^{1} \mathrm{H}$ NMR spectrum of a mixture of $0.87 \mathrm{mM}$ of $\gamma$-CD and $1 \mathrm{mM}$ of $\mathrm{CPZ}$ was recorded (Figs. 4 and 5). Results similar to those recorded for the $\beta-\mathrm{CD} / \mathrm{CPZ}$ complex were obtained, but the phenomenon was less marked. Upfield chemical shift variations of $\mathrm{H}_{1}, \mathrm{H}_{3}, \mathrm{H}_{4}$, $\mathrm{H}_{5}$ and $\mathrm{H}_{6} / \mathrm{H}_{6^{\prime}}$ protons of $\gamma$-CD were observed, together with a small 

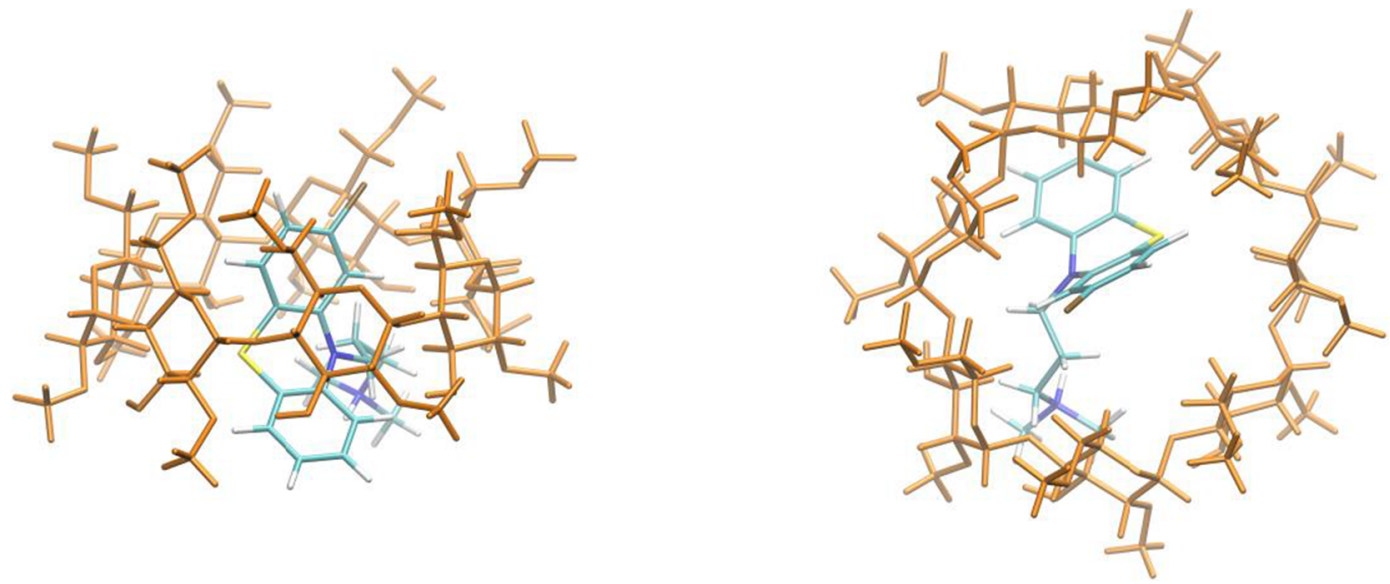

Fig. 9. Proposed molecular structure of DIME- $\beta-C D / C P Z$ complex with side and top views.

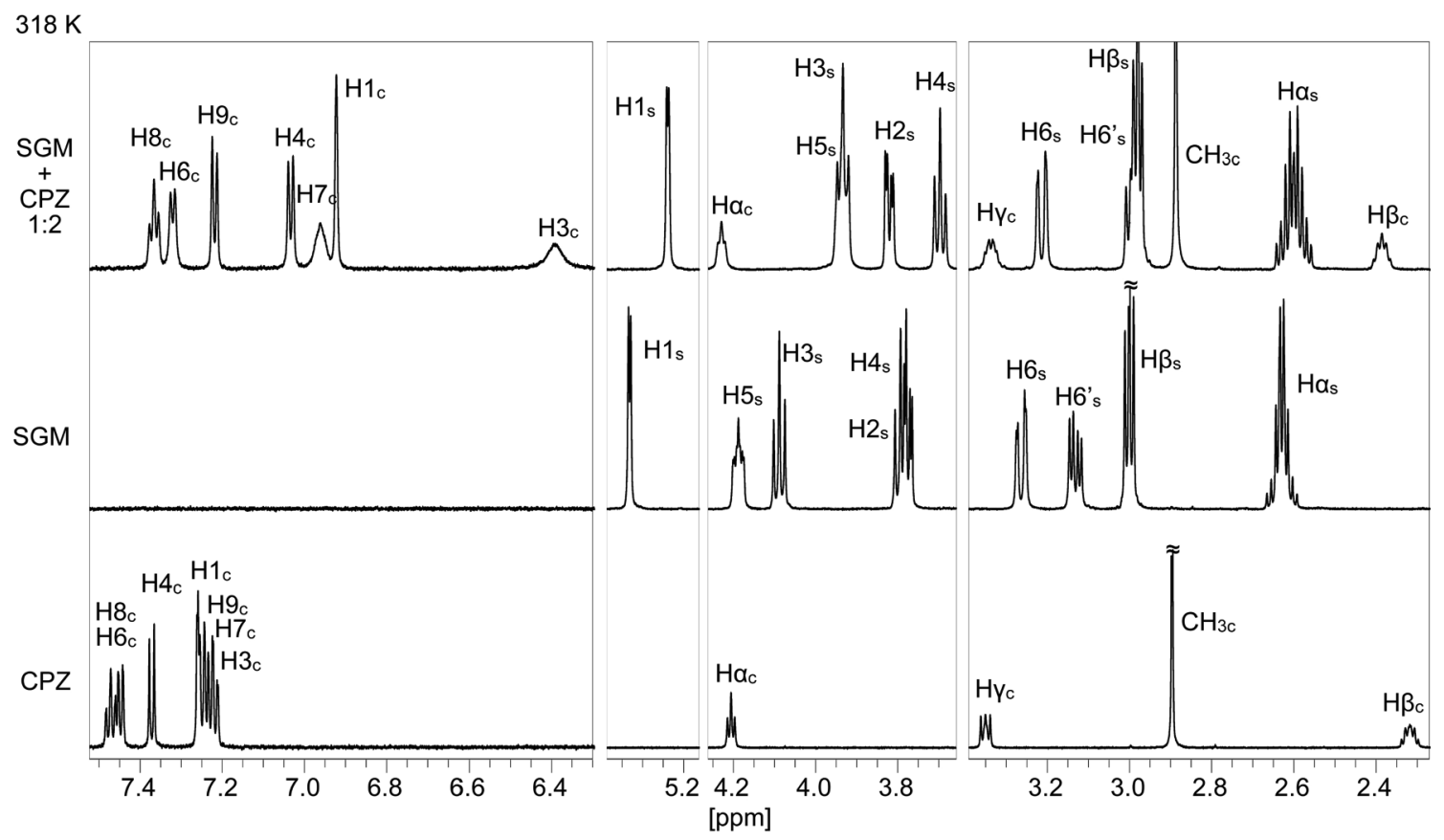

Fig. 10. ${ }^{1} \mathrm{H}$ NMR spectra of $1 \mathrm{mM}$ of $\mathrm{CPZ}, 0.5 \mathrm{mM}$ of sugammadex and a mixture of $0.5 \mathrm{mM}$ of sugammadex and $1 \mathrm{mM}$ of $\mathrm{CPZ}$ in $\mathrm{D}_{2} \mathrm{O}\left(\mathrm{T}=45{ }^{\circ} \mathrm{C}, 700 \mathrm{MHz}\right)$.

downfield chemical shift variation for the $\mathrm{H}_{2}$ protons. However, as far as the aromatic protons of $\mathrm{CPZ}$ were concerned, the situation was totally different, because upfield chemical shift variations of all the aromatic protons were detected, and this was more pronounced for the protons of the chlorinated aromatic cycle with a significant broadening of the protons $\mathrm{H}_{3}$ and $\mathrm{H}_{4}$ of $\mathrm{CPZ}$. Moreover, considering the aliphatic protons of $\mathrm{CPZ}$, upfield chemical shift variations were also observed for all methylene protons as well as for the methyl protons. In order to obtain a better description of the $\gamma$-CD/CPZ complex, 2D off-resonance ROESY spectroscopy was carried out with the same mixture (Fig. S2), but partial overlap of the $\mathrm{H}_{3}$ and $\mathrm{H}_{6} / \mathrm{H}_{6}$, proton signals of $\gamma$-CD and the coexistence of $\gamma-\mathrm{CD} / \mathrm{CPZ}$ and $\gamma-\mathrm{CD} / \mathrm{CPZ}_{2}$ complexes precluded analysis of the data. It should be noted that no cross-correlation peak was detected for the $\mathrm{H}_{3}$ and $\mathrm{H}_{7}$ protons of $\mathrm{CPZ}$ towards the internal protons of the $\gamma$-CD, probably as a result of the broadening of the $\mathrm{H}_{3}$ proton signal of $\mathrm{CPZ}$ and the probability that the $\mathrm{H}_{7}$ proton was located outside the cyclodextrin. This location was likely because only a weak cross-correlation peak was detected between the $\mathrm{H}_{8}$ proton of $\mathrm{CPZ}$ and the internal protons of the $\gamma$-CD. A measurement at a lower temperature was performed with the intent of separating the signal emanating from the free form and the complexed form for the $\mathrm{H}_{3}$ and $\mathrm{H}_{4}$ protons of $\mathrm{CPZ}$ (Fig. S3). However, this led to even more broadening of these protons and splitting of the methylene protons of the aliphatic chain of CPZ.

Furthermore, the ${ }^{1} \mathrm{H}$ NMR spectrum of the $\gamma$-CD/CPZ mixture containing a higher concentration of $\gamma$-CD was recorded (Figs. 4 and 5). In this case, the ${ }^{1} \mathrm{H}$ NMR spectrum of the $\gamma$ - $\mathrm{CD} / \mathrm{CPZ}$ mixture was very close to that of the $\gamma$-CD, which could easily be explained by the presence of $93 \%$ of free $\gamma$-CD. However, upfield chemical shift variations on the internal $\mathrm{H}_{3}, \mathrm{H}_{5}$ and $\mathrm{H}_{6} / \mathrm{H}_{6}$, protons of $\gamma$-CD were observed, confirming the formation of an inclusion complex. Concerning the aromatic protons of $\mathrm{CPZ}$, some differences as compared to the low $\gamma$-CD concentration spectrum have been identified. A downfield chemical shift variation was observed for the $\mathrm{H}_{7}$ and $\mathrm{H}_{8}$ protons of $\mathrm{CPZ}$, while a smaller upfield chemical shift variation was noticed for the $\mathrm{H}_{3}$ and $\mathrm{H}_{4}$ protons of CPZ. On the contrary, a larger upfield chemical shift variation was detected for the $\mathrm{H}_{1}$ and $\mathrm{H}_{9}$ protons of $\mathrm{CPZ}$. These differences can be explained by a larger proportion of the 1:1 complex in solution for the 10:1 mixture. Finally, our attempt to obtain additional data from a 2D off-resonance ROESY spectrum was inconclusive for similar reasons to those described above (Fig. S4), with partial overlap of the $\mathrm{H}_{5}$ 
and $\mathrm{H}_{6} / \mathrm{H}_{6^{\prime}}$ proton signals of $\gamma$-CD. As in the case of low $\gamma$-CD concentration, no cross-correlation peak was detected between the $\mathrm{H}_{3}$ and $\mathrm{H}_{7}$ protons of $\mathrm{CPZ}$ and the internal protons of $\gamma-\mathrm{CD}$, again for similar reasons. But with a high concentration of $\gamma$-CD a weak cross-correlation peak was detected between the $\mathrm{H}_{8}$ proton of $\mathrm{CPZ}$ and the $\mathrm{H}_{5}$ and $\mathrm{H}_{6} / \mathrm{H}_{6}$, protons of $\gamma$-CD. Unfortunately, no three-dimensional structure could be determined in the presence of $\gamma$-CD by 2D off-resonance ROESY spectroscopy.

In order to have an overview of the 1:1 and 1:2 complexes obtained in the presence of $\gamma$-CD, molecular modelling was undertaken taking into account as much of the NMR data as possible (Figs. S5 and S6). The lowest energy structure for each complex was determined and the experimental data are mostly in agreement with the structures obtained by molecular modelling. In both cases, the structures are in agreement with the absence of cross-correlation peaks between the internal protons of $\gamma$-CD and the aliphatic protons of CPZ, since the aliphatic chains are outside the cavity of the $\mathrm{CD}$. Furthermore, for both the 1:1 and the $1: 2$ complexes, some aromatic parts of CPZ are located outside the $\gamma$-CD cavity; this phenomenon is all the more marked for the 1:2 complex.

\subsection{Structure of the sugammadex/chlorpromazine complex}

As for the other complexes, the ${ }^{1} \mathrm{H}$ spectrum of a mixture of sugammadex and CPZ in a molar ratio $1: 2$ was recorded at $25{ }^{\circ} \mathrm{C}$ in order to compare it with the ${ }^{1} \mathrm{H}$ spectra of the compounds taken separately (Fig. S7). Partial broadening of the aromatic protons of CPZ in the presence of sugammadex was observed, in particular for the $\mathrm{H}_{6}$ and $\mathrm{H}_{8}$ protons of CPZ. An even more extensive broadening of the $\mathrm{H}_{3}$ and $\mathrm{H}_{7}$ protons of $\mathrm{CPZ}$ was also noticed, since these two protons could not be observed in the spectrum. In order to recover the signals of these protons, the temperature was increased to change their dynamic regime (Fig. 10). At $45{ }^{\circ} \mathrm{C}$, all the protons of $\mathrm{CPZ}$ could be observed in the ${ }^{1} \mathrm{H}$ spectrum of the sugammadex/CPZ mixture. In particular, the $\mathrm{H}_{3}$ and $\mathrm{H}_{7}$ protons of $\mathrm{CPZ}$ could be observed, despite considerable broadening. The other aromatic protons are much less broadened. A temperature of $45^{\circ} \mathrm{C}$ was thus chosen for later experiments unless otherwise stated. An upfield chemical shift variation of all protons of sugammadex was noticed except for the $\mathrm{H}_{2}$ protons for which a downfield chemical shift variation was observed. As far as the protons of $\mathrm{CPZ}$ were concerned, an upfield chemical shift variation of all aromatic protons was observed as well as for the methylene $\mathrm{H}_{\gamma}$ and methyl $\mathrm{CH}_{3}$ protons while the methylene $H_{\alpha}$ and $H_{\beta}$ protons were subject to a downfield chemical shift variation. With the exception of some differences at the level of the aliphatic chain, the same observations as for the $\gamma-\mathrm{CD} / \mathrm{CPZ}$ mixture containing a low concentration of $\gamma$-CD were made. In order to unambiguously confirm the formation of a unique 1:2 sugammadex/CPZ complex, the continuous variation's method, known as "Job's method", based on ${ }^{1} \mathrm{H}$ NMR titration experiments was used (Figs. S8 and S9). This method required that the total concentration of sugammadex and CPZ was kept constant $(1 \mathrm{mM})$ with the molar ratio $r_{i}$ being varied from zero to one (with $i=\mathrm{CPZ}$ or sugammadex). Plots of the observed $\Delta \delta_{i} \times[i]$ as a function of $r_{i}$ led to Job plots. Taking into account the $\mathrm{H}_{3}$ and $\mathrm{H}_{5}$ protons of sugammadex, the Job plots showed a minimum at $r_{\text {sugammadex }}=0.35$. The $\mathrm{H}_{1}, \mathrm{H}_{3}, \mathrm{H}_{4}$ and $\mathrm{H}_{7}$ protons of $\mathrm{CPZ}$ yielded a minimum at $r_{\text {chlorpromazine }}=0.65$. These values are consistent with a 1:2 stoichiometry for the complex, confirming the result obtained by ITC. This result was furthermore confirmed by DOSY measurements at $25{ }^{\circ} \mathrm{C}$ and $45{ }^{\circ} \mathrm{C}$ (Figs. S10 and S11). Indeed, at $25{ }^{\circ} \mathrm{C}$, the diffusion coefficient determined for sugammadex, with or without $\mathrm{CPZ}$, was equal to $D_{\text {sugammadex }}=(1.81 \pm 0.06) \times 10^{-10} \mathrm{~m}^{2} \cdot \mathrm{s}^{-1}$ independently of the $\mathrm{CPZ}$ concentration. For $\mathrm{CPZ}$, a diffusion coefficient equal to $D_{\text {complexed chlorpromazine }}=(1.80 \pm 0.03) \times 10^{-10} \mathrm{~m}^{2} \cdot \mathrm{s}^{-1}$ was determined for $r_{\text {chlorpromazine }}<0.7$. An increase in the amount of CPZ led to an increase in the diffusion coefficient to reach the value of the diffusion coefficient of pure $\mathrm{CPZ}, D_{\text {free chlorpromazine }}=4.68 \times 10^{-10}$ $\mathrm{m}^{2} . \mathrm{s}^{-1}$. Similar behaviour was observed at $45{ }^{\circ} \mathrm{C}$ with the following values: $D_{\text {sugammadex }}=(3.89 \pm 0.32) \times 10^{-10} \mathrm{~m}^{2} . \mathrm{s}^{-1}, D_{\text {complexed }}$ chlorpromazine $=(4.02 \pm 0.26) \times 10^{-10} \mathrm{~m}^{2} . \mathrm{s}^{-1}$ (for $\left.r_{\text {chlorpromazine }}<0.7\right)$ and $D_{\text {free chlorpromazine }}=8.57 \times 10^{-10} \mathrm{~m}^{2} . \mathrm{s}^{-1}$.

Finally, in order to obtain the three-dimensional structure of the sugammadex/CPZ complex, a 2D off-resonance ROESY spectrum was recorded for a 1:2 mixture of sugammadex and $\mathrm{CPZ}$ (Fig. 11). Due to the extensive broadening of the $\mathrm{H}_{3}$ and $\mathrm{H}_{7}$ protons of $\mathrm{CPZ}$, no cross-correlation peak could be detected for them. However, numerous other cross-correlation peaks were observed on the 2D spectrum. Firstly, one cross-correlation peak was observed between the $\mathrm{H}_{8}$ proton of $\mathrm{CPZ}$ and the $\mathrm{H}_{5}$ protons of sugammadex and another between the $\mathrm{H}_{6}$ proton of $\mathrm{CPZ}$ and the $\mathrm{H}_{3}$ protons of sugammadex. For this last CPZ proton, weak cross-correlation peaks were also observed with the $\mathrm{H}_{6}$ and $\mathrm{H}_{\beta}$ protons of sugammadex. For the other $\mathrm{CPZ}$ aromatic protons $\left(\mathrm{H}_{1}, \mathrm{H}_{4}\right.$ and $\left.\mathrm{H}_{9}\right)$, strong cross-correlation peaks were noticed with the $\mathrm{H}_{3}$ and $\mathrm{H}_{5}$ protons of $\mathrm{H}_{\beta}$ protons of sugammadex. In the case of the methylene protons of the aliphatic chain of $\mathrm{CPZ}$, a strong cross-correlation peak was observed between the $\mathrm{H}_{\alpha}$ proton of $\mathrm{CPZ}$ and the $\mathrm{H}_{3}$ and $\mathrm{H}_{5}$ protons of sugammadex, while the two other methylene protons $\mathrm{H}_{\beta}$ and $\mathrm{H}_{\gamma}$ showed weak cross-correlation peaks with the $\mathrm{H}_{3}$ and $\mathrm{H}_{5}$ protons of sugammadex. Weak cross-correlation peaks were observed for the $\mathrm{H}_{\alpha}$ and $\mathrm{H}_{\gamma}$ protons of $\mathrm{CPZ}$ towards the $\mathrm{H}_{\beta}$ protons of sugammadex and a weaker one was detected between the $\mathrm{H}_{\alpha}$ protons of $\mathrm{CPZ}$ and the $\mathrm{H}_{6}$ protons of sugammadex. It should be pointed out that $\mathrm{H}_{6^{\prime}}$ and $\mathrm{H}_{\alpha}$ of sugammadex did not show any cross-correlation peak with the protons of CPZ. In order to obtain further data, a 2D off-resonance ROESY spectrum was recorded on a 1:1 mixture, but no new information could be retrieved from this spectrum (Fig. S12). Selective 1D ROESY spectra were recorded on the 1:2 mixture of sugammadex and CPZ to complete the information provided by the 2D off-resonance ROESY spectrum (Fig. S13). From these spectra, it could be seen that the $\mathrm{H}_{6}$ and $\mathrm{H}_{8}$ protons of $\mathrm{CPZ}$ were located near the $\mathrm{H}_{3}$ and $\mathrm{H}_{5}$ protons of sugammadex. Moreover, selective excitation of the $\mathrm{H}_{\alpha}$ of the aliphatic chain of CPZ allowed us to conclude that these protons are close to the $\mathrm{H}_{3}$ protons of sugammadex. Taking into account of all these structural data, several three-dimensional models have been considered. The aliphatic chains of the two CPZ molecules are probably orientated in opposite directions, the first being near to the side-chains on the primary side of sugammadex and the second located at the secondary side of sugammadex. Moreover, the first chlorpromazine, and more precisely the chlorinated ring, is probably located in the extra cavity defined by the side-chains. Considering the second chlorpromazine molecule, $\pi-\pi$ stacking interactions are likely be involved between the unchlorinated cycle of the CPZ molecule that is deeply anchored within the cyclodextrin and the chlorinated cycle of the second CPZ molecule. Indeed, molecular modelling confirms our assumptions (Figs. 12 and S15), but it should be noted that the choice of the initial conditions strongly influences the results obtained, and more particularly the complexation of two CPZ molecules within the sugammadex cavity. $\pi-\pi$ stacking interactions were detected during the molecular dynamics simulation (Fig. S14), since the distance between the ring centroid is close to $3.60 \pm 0.22 \AA$, a distance compatible with a $\pi-\pi$ stacking interaction (Janiak, 2000). In this case, the second ring centroid distance is equal to $8.83 \pm 0.69 \AA$, showing that the two aromatic cycles are further apart. During the molecular dynamics simulation, a partial switch between the two chlorpromazine molecules was observed, leading to an equalization of the two ring centroid distances to the same distance of $4.73 \pm 0.44 \AA$ that could not provide appreciable $\pi$ - $\pi$ stacking interactions. Moreover, some hydrogen bonds between one of the CPZ molecules and sugammadex were detected during the molecular dynamics simulation (Table S1). N-H...O hydrogen bonds with the highest frequency $(23.3 \%)$ were observed between the proton of the aliphatic amine of the first CPZ molecule and the oxygen atoms of the sugammadex side-chains, leading to an average distance equal to $2.79 \AA$. Another less frequent set of $\mathrm{N}-\mathrm{H} \cdots \mathrm{O}$ hydrogen bonds were detected between the proton of the aliphatic amine of the second CPZ molecule 

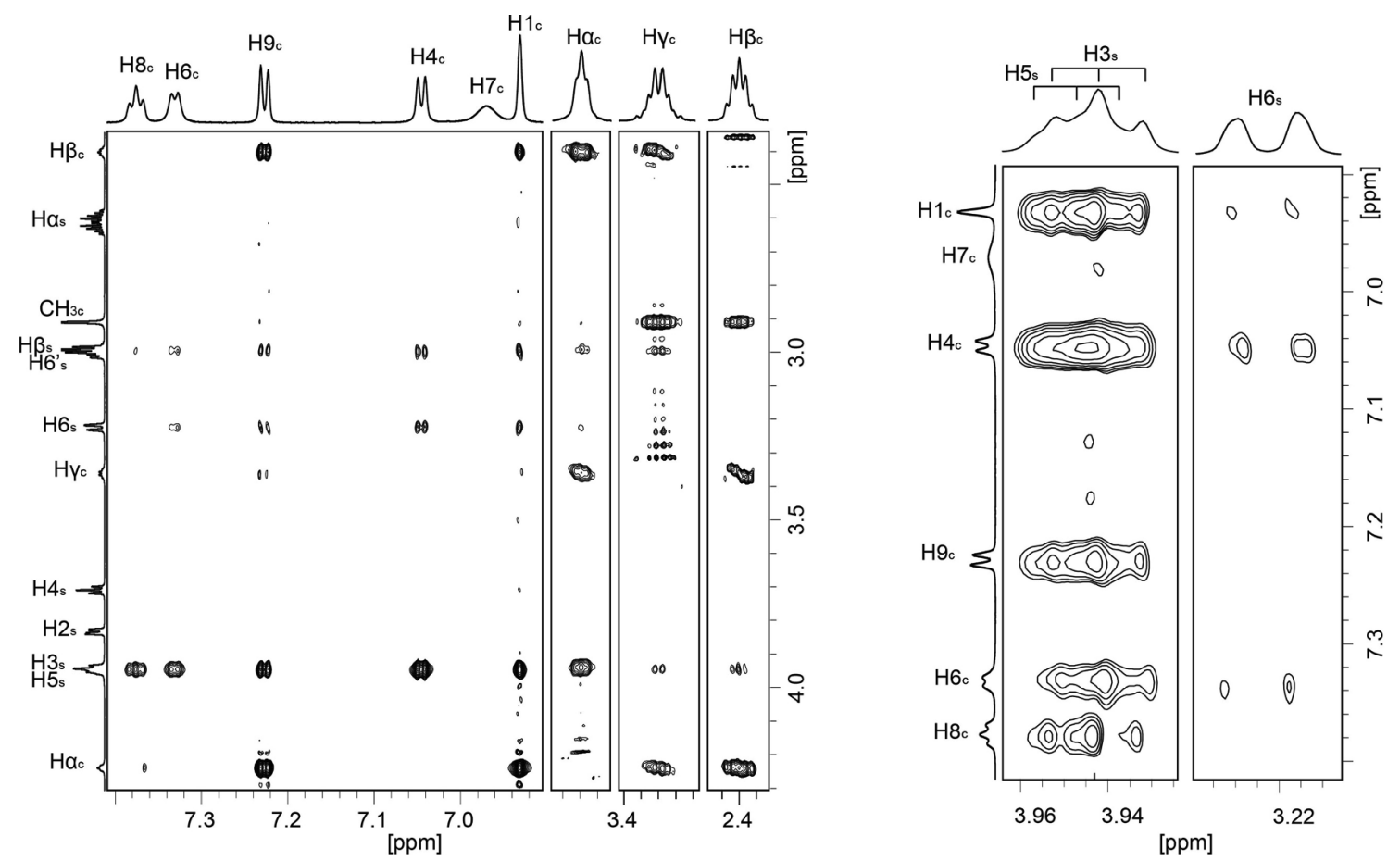

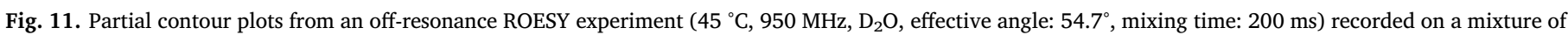
sugammadex $(0.5 \mathrm{mM})$ and $\mathrm{CPZ}(1 \mathrm{mM})$.

and the oxygen atoms of the free hydroxyl groups of the sugammadex. In the case of the hydroxyl groups located at the $\mathrm{O} 3$ positions, an average distance of $2.88 \AA$ with an occurrence frequency of $7.3 \%$ was observed while the hydroxyl groups located at the $\mathrm{O} 2$ positions lead to a lower occurrence $(6.1 \%)$ but with the same average distance $(2.88 \AA$ ).

\subsection{Impact of the presence of cyclodextrins on chlorpromazine photodegradation}

Since CPZ is photosensitive, we investigated the photodegradation of $\mathrm{CPZ}$ in presence of a series of $\mathrm{CDs}(\beta-\mathrm{CD}, \gamma-\mathrm{CD}$, DIME- $\beta-\mathrm{CD}$, SBE- $\beta-C D$, SBE- $\gamma-C D$ and sugammadex). Based on the different complexation capability, different concentrations of CDs were used to mix with $1.4 \mathrm{mM} \mathrm{CPZ}$, to obtain the same percentage (95\%) of $\mathrm{CPZ}$ that could form complexes. Photodegradation studies were performed at $254 \mathrm{~nm}$ which corresponds to the main UV-visible absorption band $\left(\log _{10} \varepsilon=4.51\right.$ at $254 \mathrm{~nm}$ and $\log _{10} \varepsilon=3.61$ at $306 \mathrm{~nm}$, see Fig. S16). As shown in Fig. 13, 78.5\% of CPZ was degraded in absence of CD after $240 \mathrm{~min}$, confirming the low photostability of CPZ. The photodegradation was enhanced in presence of all the CDs studied (see

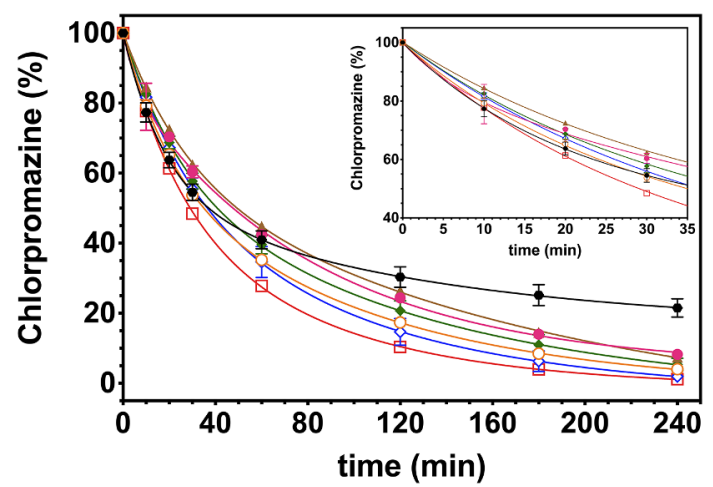

Fig. 13. Photodegradation kinetics of chlorpromazine in the absence ( ) and presence of cyclodextrins $(\beta-\mathrm{CD}=\boldsymbol{\bullet}$, DIME- $\beta-\mathrm{CD}=\boldsymbol{\Lambda}, \mathrm{SBE}-\beta-\mathrm{CD}=\boldsymbol{\gamma}, \gamma-\mathrm{CD}$ $=\mathrm{O}, \mathrm{SBE}-\gamma-\mathrm{CD}=\diamond$, sugammadex $=\square$ ) under UV light irradiation and enlarged plot from 0 to $35 \mathrm{~min}$ (inset).

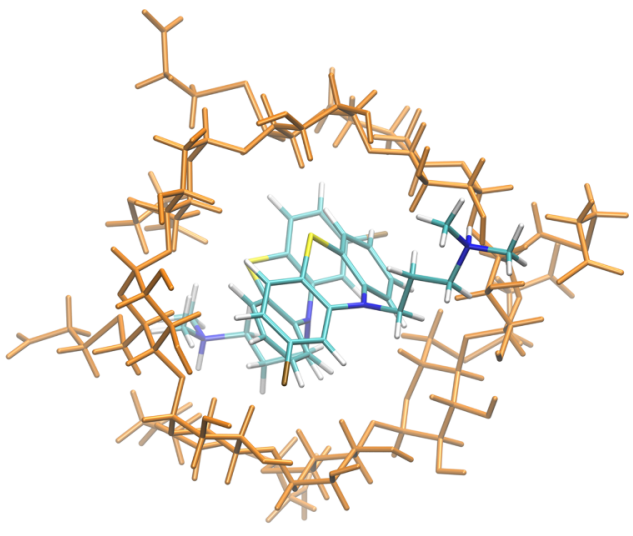

Fig. 12. Proposed molecular structure of sugammadex/CPZ complex with side and top views. 
Table 3

Photodegradation rate constants $(k)$, related half-life times $\left(t_{1 / 2}\right)$ and remaining percentage of chlorpromazine after $240 \mathrm{~min}$ in the absence and presence of cyclodextrins upon UV light irradiation.

\begin{tabular}{cccccc}
\hline Entry & CD & CD conc. & $\boldsymbol{k}^{2}$ & $\boldsymbol{t}_{\mathbf{1 / 2}}{ }^{3}$ & Res. $^{2} \mathbf{C Z}^{4}$ \\
\hline 1 & - & - & 1.28 & 32.5 & 21.5 \\
2 & $\beta-\mathrm{CD}$ & 2.9 & 1.05 & 39.6 & 8.2 \\
3 & DIME- $\beta-C D$ & 2.2 & 0.95 & 43.5 & 7.5 \\
4 & SBE- $\beta$-CD & 1.9 & 1.11 & 37.5 & 5.4 \\
5 & $\gamma-\mathrm{CD}$ & 13.5 & 1.27 & 32.9 & 4.0 \\
6 & SBE- $\gamma$-CD & 6.3 & 1.18 & 35.2 & 1.9 \\
7 & sugammadex & 0.7 & 1.46 & 28.2 & 1.1 \\
\hline
\end{tabular}

1 CD concentration (mM).

2 Initial rate constant $\left(\mathrm{h}^{-1}\right)$.

3 Initial half-life time ( $\mathrm{min})$.

${ }^{4}$ Residual CPZ after 240 min (\%).

photodegradation profile in Fig. S17) but the extent was different depending on the CD. For example, after $240 \mathrm{~min}$, only $8.2 \%$ of $\mathrm{CPZ}$ remained when $\beta$-CD was added, while this value decreased to $1.1 \%$ in presence of sugammadex, although it has the highest complexation constant with $\mathrm{CPZ}$.

Our results are in agreement with the results of the literature regarding $\gamma$-CD, but not in the case of $\beta$-CD. Indeed, Uekama et al. showed that the photodegradation of $\mathrm{CPZ}$ was enhanced in the presence of $\alpha$-CD and $\gamma-C D$, while $\beta-C D$ was able to reduce the rate of photodegradation of CPZ in phosphate buffer at pH 4.0 (Uekama et al., 1978) and these results were confirmed later by the same authors (Irie and Uekama, 1985). The same result was obtained by Ammar et al. in the presence of $\beta$-CD (Ammar et al., 1995). These differences with our results could be explained by the different experimental conditions used in each study (composition of the aqueous phase, $\mathrm{pH}$, type of reactor glass, lamp). Moreover, by monitoring the residual CPZ concentration as a function of time, we found that the degradation of $\mathrm{CPZ}$ (with or without $\mathrm{CD}$ ) follows a pseudo first-order reaction at the beginning of the experiment. The initial rate constant $k$ and corresponding $t_{1 / 2}$ are listed in Table 3 . Moreover, from the initial rate constants $k$, we found that the ratio $k_{\beta-\mathrm{CD}} / k_{\text {. }}$ was the same in our study as in the study published by Uekama et al. $\left(k_{\beta-\mathrm{CD}} / k_{-}=0.82\right.$; Uekama et al., 1978$)$ but the ratio $k_{\gamma-\mathrm{CD}} / k_{\text {. found }}$ by Uekama et al. $\left(k_{\gamma-\mathrm{CD}} / k_{-}=1.16\right.$; Uekama et al., 1978) was slightly higher compared with the value calculated from our results $\left(k_{\beta-\mathrm{CD}} / k_{-}=0.99\right)$. It should be noted that only sugammadex led to a higher value of the initial rate constant of the photodegradation of CPZ compared to the one obtained without $\mathrm{CD}$, but for reaction times greater than ca. $55 \mathrm{~min}$, a very strong decrease in the rate constant was observed for the photodegradation without $\mathrm{CD}$.

CDs act as photo-stabilizers in numerous cases (Ioele et al., 2017). For example, the photostability of Rhein, an anthraquinonic drug, was significantly improved by forming inclusion complexes with $\beta$-CD and HP- $\beta$-CD (Petralito et al., 2009). HP- $\beta$-CD also showed a protective effect on the photostability of cilnidipine (Hu et al., 2012). However, CDs may play a different role depending on sample conditions. A systematic investigation on the photostability of nicardipine was carried out by Pomponio et al., using a range of CDs and either a protective or an accelerating effect was observed depending on the CD (Pomponio et al., 2004). The mechanism by which CDs accelerate CPZ photodegradation has not yet been determined. One hypothesis could be that the $\mathrm{CD}$ acts as a catalyst during photodegradation. Indeed, Mielcarek put forward this hypothesis when studying the photodegradation of a series of 1,4-dihydropyridine derivatives in the presence of $\beta$-CD (Mielcarek, 1997). Another hypothesis could be based on the fact that, in the absence of cyclodextrin, CPZ molecules would be self-assembled in premicelles at the concentration used, as a premicellar association was reported for CPZ below the critical micellar concentration in the literature, and the photosensitive parts of $\mathrm{CPZ}$ would be protected due to molecular stacking (Attwood et al., 1994) in the self-assembled object. In presence of $C D$, it is well-known that the addition of $C D$ leads to increased critical micellar concentration, by reducing the amount of free surfactant molecules able to adsorb at interfaces by simple complexation of the surfactant molecule within the cyclodextrin cavity (Bernat et al., 2008). Thereby, as CD concentrations were chosen in order to complex $95 \%$ of $\mathrm{CPZ}$, there should be a very low amount of premicelles in solution and CPZ molecules would be present only as monomers and as inclusion complexes. So, if the guest molecule was only partially included in the $\mathrm{CD}$ cavity resulting in the photosensitive region of the molecule being exposed outside the cavity, an increase in photodegradation would be observed compared with the reaction carried out in the absence of $\mathrm{CD}$.

In order to have a better understanding of the photodegradation reaction, characterisation of the photodegradation products was performed by LC-HRMS ${ }^{n}$. Without CD, the main photodegradation product is hydroxypromazine (the position of the hydroxyl group is not known, but the product didn't correspond to 2-hydroxypromazine as the retention times of the product and of 2-hydroxypromazine are different). Some minor products such as promazine, chlorpromazine $S$-oxide and promazine $S$-oxide are detected (Figs. S17 and S18). In presence of CD (except sugammadex), the selectivity of the photodegradation reaction is totally reversed as the main photodegradation product is promazine and the minor products are hydroxypromazine, chlorpromazine $S$-oxide and promazine $S$-oxide. In the case of sugammadex, the situation is more complex as three main products are produced during the photodegradation reaction: promazine, hydroxypromazine and (2-carboxyethyl)thiopromazine which is obtained by the reaction of chlorpromazine (or promazine) with the thioether arms of sugammadex. From these results, CDs clearly play a role during the photodegradation reaction and are not just inert excipients as they are able to either increase or decrease the photodegradation rate, and even participate in the reaction.

\section{Conclusions}

ITC experiments showed that it was possible to form inclusion complexes between $\mathrm{CPZ}$ and different kinds of CDs, with variable stoichiometry (either exclusively $1: 1$ or $1: 2$, or mixtures of $1: 1$ and $1: 2$ ). Sugammadex provided the highest complexation constant. The association process was either enthalpy-driven or entropy-driven, depending on the cavity size and the chemical modification on the CDs. Structural investigation (1D ${ }^{1} \mathrm{H}$ NMR and 2D ROESY) of the inclusion complexes, complemented by molecular dynamics simulations in some cases, revealed that the different CDs included different regions or orientations of the CPZ molecule within the CD cavity. However, all investigated $\mathrm{CDs}$ also accelerated photodegradation of $\mathrm{CPZ}$. Taken together, these results indicate that $\mathrm{CD}$ complexation of $\mathrm{CPZ}$ could play a part in a repurposing strategy, but that further formulation steps will be necessary to circumvent $\mathrm{CPZ}$ photodegradation. Experiments are currently underway to show that CDs could be used in combination with liposomes to tune the availability and release of $\mathrm{CPZ}$ and therefore direct CPZ towards a specific target. The results will be communicated in due course.

\section{CRediT authorship contribution statement}

Zhiqiang Wang: Methodology, Investigation, Formal analysis, Writing - original draft. David Landy: Resources, Software, Methodology, Investigation, Formal analysis, Validation, Writing - review \& editing. Christina Sizun: Resources, Methodology, Investigation, Formal analysis, Writing - review \& editing. Christine Cézard: Resources, Software, Methodology, Investigation, Formal analysis. Audrey Solgadi: Resources, Methodology, Investigation, Formal analysis. Cédric Przybylski: Resources, Methodology, Investigation, Formal analysis, Writing - review \& editing. Luc 
Chaisemartin: Resources. Lars Herfindal: Conceptualization, Writing - review \& editing. Gillian Barratt: Conceptualization, Supervision, Methodology, Writing - original draft, Writing - review \& editing. François-Xavier Legrand: Conceptualization, Project administration, Supervision, Methodology, Resources, Investigation, Formal analysis, Validation, Visualization, Writing - original draft, Writing - review \& editing.

\section{Declaration of Competing Interest}

The authors declare that they have no known competing financial interests or personal relationships that could have appeared to influence the work reported in this paper.

\section{Acknowledgements}

Access to the $950 \mathrm{MHz}$ NMR spectrometer in Gif-sur-Yvette, supported by the IR-RMN-THC Fr3050 CNRS, is gratefully acknowledged. The calculations presented herein were performed using HPC resources from the MatriCS computing platform of Université de Picardie - Jules Verne, Amiens, France. The authors thank the "Région Île-de-France" for the financial support of the IPSIT facility. We also thank the China Scholarship Council (CSC) for ZW's PhD grant, Rosa Calderón-Jacinto for some preliminary experiments and Professor Sophie Fourmentin for valuable advice. LH thanks the Norwegian Society for Children's Cancer and the Norwegian Cancer Society for funding. Roquette Frères, Ashland Global Specialty Chemicals Inc. and Ligand Pharmaceuticals Inc. are gratefully acknowledged for generous gifts of cyclodextrins.

\section{Appendix A. Supplementary material}

Supplementary data to this article can be found online at https:// doi.org/10.1016/j.ijpharm.2020.119391.

\section{References}

Ammar, H.O., Ghorab, M., El-Nahhas, S.A., Omar, S.M., Ghorab, M.M., 1995. Improvement of some pharmaceutical properties of drugs by cyclodextrin complexation. 4. Chlorpromazine hydrochloride. Pharmazie 50, 805-808.

Andresen, V., Gjertsen, B.T., 2017. Drug repurposing for the treatment of acute myeloid leukemia. Front. Med, 4, 211.

Andresen, V., Gjertsen, B.T., 2019. Clinical trials of repurposing medicines in acute myeloid leukemia: limitations and possibilities in the age of precision Therapy. Cancer J. 25, 153-163.

Attwood, D., Waigh, R., Blundell, R., Bloor, D., Thévand, A., Boitard, E., Dubès, J.-P., Tachoire, H., 1994. ${ }^{1} \mathrm{H}$ and ${ }^{13} \mathrm{C}$ NMR studies of the self-association of chlorpromazine hydrochloride in aqueous solution. Magn. Reson. Chem. 32, 468-472.

Berendsen, H.J.C., Postma, J.P.M., van Gunsteren, W.F., Dinola, A., Haak, J.R., 1984. Molecular dynamics with coupling to an external bath. J. Chem. Phys. 81, 3684-3690.

Bernat, V., Ringard-Lefebvre, C., Le Bas, G., Perly, B., Djedaïni-Pilard, F., Lesieur, S., 2008 . Inclusion complex of $n$-octyl- $\beta$-D-glucopyranoside and $\alpha$-cyclodextrin in aqueous solutions: thermodynamic and structural characterization. Langmuir 24, 3140-3149.

Bertaut, E., Landy, D., 2014. Improving ITC studies of cyclodextrin inclusion compounds by global analysis of conventional and non-conventional experiments. Beilstein J. Org. Chem. 10, 2630-2641.

Brem, B., Gal, E., Găină, L., Silaghi-Dumitrescu, L., Fischer-Fodor, E., Tomuleasa, C.I., Grozav, A., Zaharia, V., Filip, L., Cristea, C., 2017. Novel thiazolo[5,4-b]phenothiazine derivatives: synthesis, structural characterization, and in vitro evaluation of antiproliferative activity against human leukaemia. Int. J. Mol. Sci. 18, 1365.

Brocos, P., Banquy, X., Díaz-Vergara, N., Pérez-Casas, S., Piñeiro, Á., Costas, M., 2011. A critical approach to the thermodynamic characterization of inclusion complexes: multiple-temperature isothermal titration calorimetric studies of native cyclodextrins with sodium dodecyl sulfate. J. Chem. Phys. в 115, 14381-14396.

Case, D.A., Betz, R.M., Cerutti, D.S., Cheatham III, T.E., Darden, T.A., Duke, R.E., Giese, T.J., Gohlke, H., Goetz, A.W., Homeyer, N., Izadi, S., Janowski, P., Kaus, J., Kovalenko, A., Lee, T.S., LeGrand, S., Li, P., Lin, C., Luchko, T., Luo, R., Madej, B., Mermelstein, D., Merz, K.M., Monard, G., Nguyen, H., Nguyen, H.T., Omelyan, I., Onufriev, A., Roe, D.R., Roitberg, A., Sagui, C., Simmerling, C.L., Botello-Smith, W.M., Swails, J., Walker, R.C., Wang, J., Wolf, R.M., Wu, X., Xiao, L., Kollman, P.A., 2016. AMBER 2016. University of California, San Francisco.

Cézard, C., Trivelli, X., Aubry, F., Djedaini-Pilard, F., Dupradeau, F.-Y., 2011. Molecular dynamics studies of native and substituted cyclodextrins in different media: 1 . Charge derivation and force field performances. Phys. Chem. Chem. Phys. 13, 15103-15121.

Clarke, R.J., Coates, J.H., Lincoln, S.F., 1986. Complexation of roccellin by $\beta$ - and $\gamma$ cyclodextrin. J. Chem. Soc., Faraday Trans. 1 82, 2333-2343.

Desvaux, H., Berthault, P., Birlirakis, N., Goldman, M., Piotto, M., 1995. Improved versions of off-resonance ROESY. J. Magn. Reson. A 113, 47-52.

Döhner, H., Estey, E.H., Amadori, S., Appelbaum, F.R., Büchner, T., Burnett, A.K., Dombret, H., Fenaux, P., Grimwade, D., Larson, R.A., Lo-Coco, F., Naoe, T., Niederwieser, D., Ossenkoppele, G.J., Sanz, M.A., Sierra, J., Tallman, M.S., Löwenberg, B., Bloomfield, C.D., 2010. Diagnosis and management of acute myeloid leukemia in adults: Recommendations from an international expert panel, on behalf of the European LeukemiaNet. Blood 115, 453-474.

Dupradeau, F.-Y., Cézard, C., Lelong, R., Stanislawiak, E., Pêcher, J., Delepine, J.C., Cieplak, P., 2008. R.E.DD.B.: A database for RESP and ESP atomic charges, and force field libraries. Nucleic Acids Res. 36, D360-D367.

Essmann, U., Perera, L., Berkowitz, M.L., Darden, T.A., Lee, H., Pedersen, L.G., 1995. A smooth particle mesh Ewald method. J. Chem. Phys. 103, 8577.

Frisch, M.J., Trucks, G.W., Schlegel, H.B., Scuseria, G.E., Robb, M.A., Cheeseman, J.R., Scalmani, G., Barone, V., Mennucci, B., Petersson, G.A., Nakatsuji, H., Caricato, M., Li, X., Hratchian, H.P., Izmaylov, A.F., Bloino, J., Zheng, G., Sonnenberg, J.L., Hada, M., Ehara, M., Toyota, K., Fukuda, R., Hasegawa, J., Ishida, M., Nakajima, T., Honda, Y., Kitao, O., Nakai, H., Vreven, T., Montgomery Jr., J.A., Peralta, J.E., Ogliaro, F., Bearpark, M.J., Heyd, J., Brothers, E.N., Kudin, K.N., Staroverov, V.N., Kobayashi, R., Normand, J., Raghavachari, K., Rendell, A.P., Burant, J.C., Iyengar, S.S., Tomasi, J., Cossi, M., Rega, N., Millam, N.J., Klene, M., Knox, J.E., Cross, J.B., Bakken, V., Adamo, C., Jaramillo, J., Gomperts, R., Stratmann, R.E., Yazyev, O., Austin, A.J., Cammi, R., Pomelli, C., Ochterski, J.W., Martin, R.L., Morokuma, K., Zakrzewski, V.G., Voth, G.A., Salvador, P., Dannenberg, J.J., Dapprich, S., Daniels, A.D., Farkas, Ö., Foresman, J.B., Ortiz, J.V., Cioslowski, J., Fox, D.J., 2009. Gaussian 09, Revision D.01. Gaussian Inc., Wallingford, CT, USA.

Gharib, R., Greige-Gerges, H., Fourmentin, S., Charcosset, C., Auezova, L., 2015. Liposomes incorporating cyclodextrin-drug inclusion complexes: current state of knowledge. Carbohydr. Polym. 129, 175-186.

Hardee, G.E., Otagiri, M., Perrin, J.H., 1978. Microcalorimetric investigations of pharmaceutical complexes. I. Drugs and $\beta$-cyclodextrin. Acta Pharm. Suec. 15, 188-199.

Hirai, H., Toshima, N., Uenoyama, S., 1981. Inclusion complex formation of cyclodextrin with large dye molecule. Polymer J. 13, 607-610.

Hoshino, T., Ishida, K., Irie, T., Uekama, K., Ono, T., 1989. An attempt to reduce the photosensitizing potential of chlorpromazine with the simultaneous use of $\beta$ - and dimethyl- $\beta$-cyclodextrins in guinea pigs. Arch. Dermatol. Res. 281, 60-65.

Hu, L., Zhang, H., Song, W., Gu, D., Hu, Q., 2012. Investigation of inclusion complex of cilnidipine with hydroxypropyl- $\beta$-cyclodextrin. Carbohydr. Polym. 90, 1719-1724.

Ioele, G., De Luca, M., Garofalo, A., Ragno, G., 2017. Photosensitive drugs: a review on their photoprotection by liposomes and cyclodextrins. Drug Delivery 24, 33-44.

Irie, T., Uekama, K., 1985. Protection against the photosensitized skin irritancy of chlorpromazine by cyclodextrin complexation. J. Pharmacobiodyn. 8, 788-791.

Ishida, K., Hoshino, T., Irie, T., Uekama, K., 1988. Alleviation of chlorpromazine-photosensitized contact dermatitis by $\beta$-cyclodextrin derivatives and their possible mechanisms. Drug Metab. Pharmacokinet. 3, 377-386.

Janiak, C., 2000. A critical account on $\pi-\pi$ stacking in metal complexes with aromatic nitrogen-containing ligands. J. Chem. Soc., Dalton. Trans. 3885-3896.

Jaszczyszyn, A., Gąsiorowski, K., Świątek, P., Malinka, W., Cieślik-Boczula, K., Petrus, J. Czarnik-Matusewicz, B., 2012. Chemical structure of phenothiazines and their biological activity. Pharmacol. Rep. 64, 16-23.

Johnson Jr., C.S., 1999. Diffusion ordered nuclear magnetic resonance spectroscopy: principles and applications. Prog. Nucl. Magn. Reson. Spectrosc. 34, 203-256.

Jorgensen, W.L., Chandrasekhar, J., Madura, J.D., Impey, R.W., Klein, M.L., 1983 Comparison of simple potential functions for simulating liquid water. J. Chem. Phys. 79, 926-935.

Juliusson, G., Antunovic, P., Derolf, A., Lehmann, S., Möllgård, L., Stockelberg, D., Tidefelt, U., Wahlin, A., Höglund, M., 2009. Age and acute myeloid leukemia: real world data on decision to treat and outcomes from the swedish acute leukemia registry. Blood 113, 4179-4187.

Kitamura, K., Imayoshi, N., 1992. Second-derivative spectrophotometric determination of the binding constant between chlorpromazine and $\beta$-cyclodextrin in aqueous solutions. Anal. Sci. 8, 497-501.

Lichtman, M.A., 2013. A historical perspective on the development of the cytarabine (7days) and daunorubicin (3days) treatment regimen for acute myelogenous leukemia: 2013 the $40^{\text {th }}$ anniversary of $7+3$. Blood Cells Mol. Dis. 50, 119-130.

McCormack, B., Gregoriadis, G., 1994. Drugs-in-cyclodextrins-in liposomes: a novel concept in drug delivery. Int. J. Pharm. 112, 249-258.

Mielcarek, J., 1997. Photochemical stability of the inclusion complexes formed by modified 1,4-dihydropyridine derivatives with $\beta$-cyclodextrin. J. Pharm. Biomed. Anal. 15, 681-686.

O'Connor, A.E., Gallagher, W.M., Byrne, A.T., 2009. Porphyrin and nonporphyrin photosensitizers in oncology: preclinical and clinical advances in photodynamic therapy. Photochem. Photobiol. 2009 (85), 1053-1074.

Okimoto, K., Ohike, A., Ibuki, R., Aoki, O., Ohnishi, N., Irie, T., Uekama, K., Rajewski, R.A., Stella, V.J., 1999. Design and evaluation of an osmotic pump tablet (OPT) for chlorpromazine using (SBE) $7 \mathrm{~m}-\beta-C D$. Pharm. Res. 16, 549-554.

Otagiri, M., Ukema, K., Ikeda, K., 1975. Inclusion complexes of $\beta$-cyclodextrin with tranquilizing drugs phenothiazines in aqueous solution. Chem. Pharm. Bull. 23, 188-195.

Petralito, S., Zanardi, I., Memoli, A., Annesini, M.C., Travagli, V., 2009. Solubility, spectroscopic properties and photostability of Rhein/cyclodextrin inclusion complex. Spectrochim. Acta A 74, 1254-1259.

Piñero, L.E., Lebrón, I., Correa, J., Díaz, J., Viera, L., Arce, R., García, C., Oyola, R. 2012. 
The effect of 2-hydroxypropyl- $\beta$-cyclodextrin on the excited triplet state of promazine and chlorpromazine. J. Photochem. Photobiol. A: Chem. 228, 44-50.

Pomponio, R., Gotti, R., Fiori, J., Cavrini, V., Mura, P., Cirri, M., Maestrelli, F., 2004 Photostability studies on nicardipine-cyclodextrin complexes by capillary electrophoresis. J. Pharm. Biomed. Anal. 35, 267-275.

Rai, S., Tanaka, H., Suzuki, M., Tanimura, A., Matsui, K., Watanabe, T., Kanakura, Y., Matsumura, I., 2014. Chlorpromazine, an inhibitor of intracellular trafficking of FLT3-ITD and KIT D816V, shows prominent anti-leukemic activities against AML cells and AML stem cells in vitro and in vivo. Blood 124, 269.

Rekharsky, M.V., Inoue, Y., 1998. Complexation thermodynamics of cyclodextrins. Chem. Rev. 98, 1875-1918.

Roe, D.R., Cheatham, T.E., 2013. PTRAJ and CPPTRAJ: software for processing and analysis of molecular dynamics trajectory data. J. Chem. Theory Comput. 9, 3084-3095.

Ryckaert, J.P., Ciccotti, G., Berendsen, H.J.C., 1977. Numerical integration of the cartesian equations of motion of a system with constraints: molecular dynamics of $n$-alkanes. J. Comput. Phys. 23, 327-341.

Schönbeck, C., Westh, P., Madsen, J.C., Larsen, K.L., Städe, L.W., Holm, R., 2011. Methylated $\beta$-cyclodextrins: influence of degree and pattern of substitution on the thermodynamics of complexation with tauro- and glyco-conjugated bile salts. Langmuir 27, 5832-5841.

Schönbeck, C., Westh, P., Holm, R., 2014. Complexation thermodynamics of modified cyclodextrins: extended cavities and distorted structures. J. Phys. Chem. B 118, 10120-10129.

Shiotani, K., Uehata, K., Irie, T., Hirayma, F., Uekama, K., 1994. Characterization of the inclusion mode of $\beta$-cyclodextrin sulfate and its effect on the chlorpromazine-induced hemolysis of rabbit erythrocytes. Chem. Pharm. Bull. 1994 (42), 2332-2337.

Syed, S.K., Christopherson, R.I., Roufogalis, B.D., 1998. Reversal of vinblastine transport by chlorpromazine in membrane vesicles from multidrug-resistant human CCRF-CEM leukaemia cells. Br. J. Cancer 78, 321-327.

Takamura, K., Inoue, S., Kusu, F., 1983. Two-guest inclusion of $\gamma$-cyclodextrin with chlorpromazine. Chem. Lett. 12, 233-236.

Takisawa, N., Shirahama, K., Tanaka, I., 1993. Interactions of amphiphilic drugs with $\alpha$-, $\beta$-, and $\gamma$-cyclodextrins. Colloid Polym. Sci. 271, 499-506.

Tellinghuisen, J., 2005. Optimizing experimental parameters in isothermal titration calorimetry. J. Phys. Chem. B 109, 20027-20035.

Uekama, K., Irie, T., Hirayama, F., 1978. Participation of cyclodextrin inclusion catalysis in photolysis of chlorpromazine to give promazine in aqueous solution. Chem. Lett. 7 1109-1112.

Uekama, K., Irie, T., Sunada, M., Otagiri, M., Iwasaki, K., Okano, Y., Miyata, T., Kasé, Y., 1981. Effects of cyclodextrins on chlorpromazine-induced haemolysis and central nervous system responses. J. Pharm. Pharmacol. 33, 707-710.

Wang, J.M., Wolf, R.M., Caldwell, J.W., Kollman, P.A., Case, D.A., 2004. Development and testing of a general amber force field. J. Comput. Chem. 2004 (25), 1157-1174.

Xu, H., Rodríguez-Hermida, S., Pérez-Carvajal, J., Juanhuix, J., Imaz, I., Maspoch, D. 2016. A first cyclodextrin-transition metal coordination polymer. Cryst. Growth Des. $16,5598-5602$.

Zhao, Y., Truhlar, D.G., 2008. The M06 suite of density functionals for main group thermochemistry, thermochemical kinetics, noncovalent interactions, excited states, and transition elements: two new functionals and systematic testing of four M06-class functionals and 12 other functionals. Theor. Chem. Acc. 120, 215-241.

Zhelev, Z., Ohba, H., Bakalova, R., Hadjimitova, V., Ishikawa, M., Shinohara, Y., Baba, Y., 2004. Phenothiazines suppress proliferation and induce apoptosis in cultured leukemic cells without any influence on the viability of normal lymphocytes. Phenothiazines and leukemia. Cancer Chemother. Pharmacol. 53, 267-275. 